\title{
Revisiting the Electrochemical Oxidation of Ammonia on Carbon-supported Metal Nanoparticle Catalysts
}

\author{
Zhe-Fei Li, Yuxuan Wang, and Gerardine G. Botte ${ }^{1^{*}}$
}




\begin{abstract}
The ammonia electro-oxidation reaction (AOR) has been studied due to its promising applications in ammonia electrolysis, wastewater remediation, direct ammonia fuel cells, and sensors. However, it is difficult to compare and analyze the reported electrocatalytic activity of AOR reliably, likely due to the variation in catalyst synthesis, electrode composition, electrode morphology, and testing protocol. In this paper, the electro-oxidation of ammonia on different carbon-supported precious metal nanoparticle catalysts was revisited. The effect of experimental conditions, electrochemical test parameters, electrocatalytic activity, thermodynamics, and possible deactivation mechanism of the catalysts were investigated. $\mathrm{Pt} / \mathrm{C}$ catalyst possesses the highest electrocatalytic activity, while $\mathrm{Ir} / \mathrm{C}$ and $\mathrm{Rh} / \mathrm{C}$ show lower overpotential. The onset potential of the AOR is related to the hydrogen binding energy of the catalyst. $\mathrm{N}_{\text {ads }}$ is one major cause of deactivation accompanied with the formation of surface $\mathrm{O} / \mathrm{OH}_{\mathrm{ads}}$ at high potentials. The coulombic efficiency of $\mathrm{N}_{\mathrm{ads}}$ formation on $\mathrm{Pt}$ is about $1 \%$ initially and gradually decreases with reaction time. Increase in ammonia concentration leads to increase in current density, while increase in hydroxyl ions concentration can enhance the current density and reduce the overpotential simultaneously. The slopes of AOR onset potential and hydrogen adsorption/desorption potential of $\mathrm{Pt} / \mathrm{C}$ as a function of $\mathrm{pH}$ follow Nernst equation. In contrast, potentials measured at different current densities exhibit non-Nernstian behavior, suggesting a critical role of the local $\mathrm{pH}$ change.
\end{abstract}

Keywords: ammonia electro-oxidation; Pt catalyst; ammonia electrolysis; ammonia fuel cells; ammonia sensors 


\section{Introduction}

Due to rapid increase in environmental and energy issues, it is required to replace conventional fossil fuels with renewable energy sources. Ammonia is regarded as a potential energy carrier for renewable energy due to its higher volumetric energy density and easier handling and transportation than hydrogen.[1,2] Over the past few decades, the electrochemical oxidation of ammonia has attracted much attention due to its potential application in fuel cells,[3-7] ammonia electrolysis,[8-10] wastewater remediation,[11-15] and sensors,[16, 17]. Ammonia can be electrochemically oxidized into nitrogen by noble transitional metal electrocatalysts (i.e. Pt, Ir, Rh, Pd) in alkaline solutions.[18, 19] The half-reaction is expressed as

$$
\mathrm{NH}_{3}+3 \mathrm{OH}^{-} \rightleftharpoons \frac{1}{2} \mathrm{~N}_{2}+3 \mathrm{H}_{2} \mathrm{O}+3 e^{-}
$$

Among these candidate metals, Pt based catalysts have been found to be the most promising catalysts.[19] However, the electrochemical oxidation of ammonia on Pt has a sluggish kinetics due to the complicated multistep electron and proton transfer process as well as difficult dimerization reaction.[20] In order to achieve high activity, tremendous efforts have been made on the development of more active electrocatalysts, include alloying of Pt with other metals (e.g., Ir, Rh, Pd, Ru) that have a potential synergistic effect with $\mathrm{Pt}$ for ammonia oxidation, $[13,21-23]$ enhancing the number of active sites by controlling the surface structure of the electrocatalysts (preferential orientation, shape, morphology, etc.),[24-26] as well as using metal oxides (e.g., $\mathrm{CeO}_{2}$, antimony-tin oxide) to enhance local hydroxide concentration.[27, 28] Yet, none catalysts have shown satisfactory performance comparable to the hydrogen oxidation reaction. Besides, Pt catalysts suffer from activity degradation due to poisonous $\mathrm{N}_{\text {ads }}$ species.[19, 29] Therefore, further development of highly active and durable catalysts is demanded.

Another concern lies in the lack of consistency in the electrocatalytic activity for ammonia 
oxidation reaction (AOR) reported by the literature. Cyclic voltammetry (CV) has been widely adopted as a simple method to identify the electrocatalytic activity of a catalyst. However, the reported activity of different Pt catalysts in the literature varies largely.[5, 7, 21, 23, 27, 30-33] This deviation is even larger for Pt-based alloy catalysts. For instance, Miura et al. discovered that $\mathrm{Pt}_{0.2} \mathrm{Ir}_{0.8}$ was the best electrocatalyst for AOR,[21] while Vidal-Iglesias et al. found that $\mathrm{Pt}_{75} \mathrm{I}_{25}$ and $\mathrm{Pt}_{75} \mathrm{Rh}_{25}$ produce higher current densities than that for Pt nanoparticles and other $\mathrm{Pt}$ alloys in the lower overpotential region.[5] It is later reported that the maximum fuel cell performance was obtained using a Pt:Ir catalyst with atomic ratio of 50:50.[7] It is thus difficult to compare and analyze the reported electrocatalytic activity of AOR reliably, likely due to the variation in catalyst synthesis, electrode composition, testing protocol, electrode morphology, crystal structure, etc. Further design and preparation of more active and durable catalysts requires a reliable electroactivity baseline for AOR. Therefore, it is highly desirable to revisit the electrochemical oxidation of ammonia and examine its real performance.

In this work, carbon supported metal nanoparticle (Pt, Ir, Rh) catalysts are synthesized using a modified poly-ol method. These catalysts exhibit small particle size and uniform particle size distribution, allowing us to compare and analyze the performance of these catalysts. These catalysts are evaluated for AOR in alkaline solution using CV. The electrocatalytic activity, thermodynamics, possible deactivation mechanism of these catalysts are studied and elucidated as follows.

\section{Experimental}

\subsection{Materials}

$\mathrm{H}_{2} \mathrm{PtCl}_{6}$ hydrate (ca. 40\% Pt, Catalog No. AC195370050), $\mathrm{IrCl}_{3}$ trihydrate (53-56\% Ir, 
Catalog No. AC195500050), $\mathrm{RhCl}_{3}$ hydrates (ca. 38\% Rh, Catalog No. AC195520010), ethylene glycol (99.5\%, Catalog No. AC295530250) were purchased from Acros Organics. Vulcan XC72 carbon black was donated by Cabot Corp. (Lot No. 3709428). Isopropanol (Certified ACS, Catalog No. A416-20), ethanol (Histological, Catalog No. A405-20), ammonium hydroxide (Catalog No. A669-212) and $1 \mathrm{~N} \mathrm{KOH}$ solution (Catalog No. SP208-500) were obtained from Fisher Chemical. Nafion solution (5 wt\%, Catalog No. 527084) was purchased from SigmaAldrich.

\subsection{Catalyst synthesis}

Carbon-supported Pt, Ir, and Rh catalysts were prepared by a modified polyol reduction method.[7, 23] $\mathrm{H}_{2} \mathrm{PtCl}_{6}$ hydrate, $\mathrm{IrCl}_{3}$ trihydrate, and $\mathrm{RhCl}_{3}$ hydrates were used as metal precursors. Vulcan XC-72 was first dispersed in ethylene glycol by ultrasonication in a Branson CPX2800 bath sonicator for $1 \mathrm{~h}$ at a concentration of $2 \mathrm{mg} \mathrm{mL}^{-1}$, followed by addition of certain amount of metal precursors to achieve the desired $20 \mathrm{wt} \%$ loading. The $\mathrm{pH}$ was adjusted above 8 with $1 \mathrm{M} \mathrm{KOH}$ solution. Then, the mixture was stirred at $300 \mathrm{rpm}$ and refluxed for $3 \mathrm{~h}\left(160{ }^{\circ} \mathrm{C}\right.$ for $\mathrm{Pt}, 180{ }^{\circ} \mathrm{C}$ for Ir and $\mathrm{Rh}$ ). After the reaction was complete, the solids were collected by filtration with a Sartorius $0.2 \mu$ m nylon filter membrane and washed with copious DI water (18 $\mathrm{M} \Omega$ ) and ethanol. Finally, the obtained catalysts were dried in a vacuum oven (MTI EQ-DZF6050-UL) at $80{ }^{\circ} \mathrm{C}$ for $24 \mathrm{~h}$.

\subsection{Characterization}

The morphology of the catalysts was characterized using a JEOL 2100F transmission electron microscopy (TEM). The particle size distribution was obtained based on randomly 
measuring more than 200 primary nanoparticles in TEM images using ImageJ. The electrochemical performance was obtained in a three-electrode electrochemical cell using a glassy carbon rotating disk electrode (RDE) $\left(0.196 \mathrm{~cm}^{2}\right.$, Pine Instruments E3 series). The RDE was polished with $0.3 \mu \mathrm{m}$ and $0.05 \mu \mathrm{m}$ alumina suspension (Electron Microscopy Sciences) to obtain a mirror-like finish. To prepare the catalyst ink, the catalyst and $20 \mathrm{wt} \%$ Nafion ionomer were added into an isopropanol/water mixture (1:4 v:v) and sonicated for 30 mins. A $10 \mu \mathrm{L}$ dispersion was dropped onto the glassy carbon electrode and dried at ambient condition. The mass loading of the precious metal was estimated to be about $30.6 \mu \mathrm{g} \mathrm{cm}^{-2}$. A Pt wire $(\mathrm{CH}$ Instruments, $99.99 \%, 0.5 \mathrm{~mm}$ diameter, $23 \mathrm{~cm}$ long) was used as the counter electrode, and $\mathrm{Hg} / \mathrm{HgO}$ (1 M KOH, CH Instruments) or reversible hydrogen electrode (RHE, Hydroflex ${ }^{\mathrm{TM}}$ ) was used as the reference electrode. All potentials reported in this work are referred to the SHE scale, unless otherwise stated. Electrochemical tests were measured by a Solartron 1480E potentiostat. Prior to the electrochemical tests, the Pt and Rh catalysts were electrochemically cleaned from $0.9 \mathrm{~V}$ to $0.3 \mathrm{~V}$ vs. $\mathrm{Hg} / \mathrm{HgO}$ in $1 \mathrm{M} \mathrm{KOH}$ or from $0 \mathrm{~V}$ to $1.2 \mathrm{~V}$ vs. $\mathrm{RHE}$ in $0.1 \mathrm{M} \mathrm{HClO}_{4}$ at 500 $\mathrm{mV} \mathrm{s}^{-1}$ until the $\mathrm{CV}$ curve remained stable and electrochemically reduced at $-0.9 \mathrm{~V}$ vs. $\mathrm{Hg} / \mathrm{HgO}$ $(1 \mathrm{M} \mathrm{KOH})$ for 1 min before AOR test. Ir catalysts were electrochemically cleaned from $-0.9 \mathrm{~V}$ to $-0.1 \mathrm{~V}$ vs. $\mathrm{Hg} / \mathrm{HgO}$ in $1 \mathrm{M} \mathrm{KOH}$ or from $0 \mathrm{~V}$ to $0.8 \mathrm{~V}$ vs. RHE in $0.05 \mathrm{M} \mathrm{H}_{2} \mathrm{SO}_{4}$ to avoid $\mathrm{Ir}$ oxidation at $500 \mathrm{mV} \mathrm{s}^{-1}$ until the $\mathrm{CV}$ curve remained stable and electrochemically reduced at -0.9 V vs. $\mathrm{Hg} / \mathrm{HgO}(1 \mathrm{M} \mathrm{KOH})$ for 1 min before AOR test.

\section{Results and Discussion}

The representative TEM images and corresponding particle size distribution of the catalysts are shown in Fig. 1. It can be seen that the metal nanoparticles are well dispersed on the carbon 
support except that there is some nanoparticle aggregation for the $\mathrm{Rh} / \mathrm{C}$ catalyst. The average particles size for $\mathrm{Pt} / \mathrm{C}, \mathrm{Ir} / \mathrm{C}, \mathrm{Rh} / \mathrm{C}$ are calculated to be about $2.7,2.2,3.7 \mathrm{~nm}$, respectively. Although there is slight difference in particle size and distribution, this difference is not significant enough to cause major deviation in electrocatalytic activity. The catalysts were used to study the electrochemical oxidation of ammonia in alkaline solution.

Insert Fig. 1.

Electrochemical measurements were conducted by $\mathrm{CV}$ scans at a scan rate of $20 \mathrm{mV} \mathrm{s}^{-1}$ in $\mathrm{HClO}_{4}$ for $\mathrm{Pt} / \mathrm{C}$ and $\mathrm{Rh} / \mathrm{C}$ catalysts and $\mathrm{H}_{2} \mathrm{SO}_{4}$ for $\mathrm{Ir} / \mathrm{C}$ catalyst, shown in Fig. 2. The electrochemical surface area (ECSA) was determined by measuring the integration of hydrogen adsorption-desorption area after double layer correction, assuming charge densities of $210 \mu \mathrm{C}$ $\mathrm{cm}_{\mathrm{Pt}}^{-2}, 218 \mu \mathrm{C} \mathrm{cm}_{\mathrm{Ir}}^{-2}$, and $221 \mu \mathrm{C} \mathrm{cm}{ }_{\mathrm{Rh}}^{-2}$, respectively.[34, 35] The ECSA for Pt/C, Ir/C, and $\mathrm{Rh} / \mathrm{C}$ were calculated to be about 72,85 , and $67 \mathrm{~m}^{2} \mathrm{~g}^{-1}$, respectively. The high surface area is consistent with the uniform distribution of nanoparticles, as shown in the TEM results.

Insert Fig. 2.

\subsection{Electrochemical oxidation of ammonia on Pt/C electrode}

The electrochemical performance of AOR by a Pt/C electrode was evaluated by CV scan in 1 $\mathrm{M} \mathrm{KOH}$ in the presence and absence of $1 \mathrm{M} \mathrm{NH}_{3}$ at room temperature and corresponding $\mathrm{CV}$ curves are shown in Fig. 3. The Pt/C electrode was electrochemically cleaned and fully reduced before any electrochemical measurement. A starting voltage of $-0.46 \mathrm{~V}$ vs. SHE, which is close 
to the zero charge potential of $\mathrm{Pt}$, was used in all $\mathrm{CV}$ scans for $\mathrm{AOR}$ to avoid $\mathrm{H}^{+}$adsorption, $\mathrm{OH}^{-}$ adsorption, and ammonia oxidation.[36] Comparing CV curves in the presence and absence of $\mathrm{NH}_{3}$ (Fig. 3a), it can be seen that the hydrogen adsorption/desorption peak shifted to a lower potential (from $-0.59 \mathrm{~V}$ vs. SHE with $\mathrm{KOH}$ to $-0.7 \mathrm{~V}$ vs. SHE with $\mathrm{NH}_{3}$ and $\mathrm{KOH}$ ), which suggests that the presence of ammonia/ammonium ions may influence the hydrogen binding energy and consequently hydrogen adsorption/desorption potential. The onset potential of AOR (defined as the potential when the anodic current density starts increasing), is around $-0.46 \mathrm{~V}$ vs. SHE, which is very close to potential of zero charge (PZC) of Pt and more than $300 \mathrm{mV}$ higher than theoretical value $(-0.77 \mathrm{~V}$ vs. SHE at $\mathrm{pH} 14)$. This may imply that ammonia oxidation takes place only after hydrogen atoms desorb from the Pt surface.[37] There is a small pre-peak (at about -0.4 vs. SHE) prior to the major AOR peak, which has been ascribed to the ammonia adsorption on Pt surfaces.[25, 37] However, the origin of this pre-peak is still not completely clear and beyond the scope of this work. The AOR peaked at about $-0.153 \mathrm{~V}$ vs. SHE and started to deactivate at potentials above that. It is also observed that the AOR current density of $\mathrm{Pt} / \mathrm{C}$ catalyst decreases with the number of CV cycles. Several authors have reported the deactivation of Pt catalyst and ascribed this deactivation to $\mathrm{N}_{\text {ads }}$ poisoning and diffusion. $[6,19,29,38]$ The origin of this deactivation was investigated and the results are presented later.

The difference in cathodic scan between $-0.8 \mathrm{~V}$ and $-0.5 \mathrm{~V}$ (highlighted by the dashed circle in Fig. 3a) suggests the existence of poisonous adsorbates AOR.[19] Since the deactivated electrode cannot be recovered after 10 mins hold at OCV (Fig. 3b), diffusion is not likely the dominant cause of degradation as a function of cycle number. A facile method to recover the catalyst by applying a reduction potential at $-0.8 \mathrm{~V}$ is demonstrated and shown in Fig. $3 \mathrm{~b}$. After holding at $-0.8 \mathrm{~V}$ for $1 \mathrm{~min}$, the deactivated $\mathrm{Pt} / \mathrm{C}$ electrode can be fully recovered and its $\mathrm{CV}$ 
curve is identical to that of a fresh electrode. The residual poisonous adsorbates after ammonia oxidation test may be one major cause for deviation in AOR performance reported in the literature. Thus, it is necessary to recover the catalyst after each electrochemical test if the same electrode will be used in subsequent tests. Otherwise, a fresh electrode should be used and a proper electrochemical cleaning procedure should be followed. (See experimental section for more details.)

Insert Fig. 3.

As mentioned earlier, AOR suffered from deactivation from possible adsorption of intermediates. To investigate the effect of intermediates on AOR, cyclic voltammograms in $1 \mathrm{M}$ ammonia and $1 \mathrm{M} \mathrm{KOH}$ solution with a constant lower potential limit of $-0.8 \mathrm{~V}$ and various upper switch potentials were measured and first-cycle CV curves are shown in Fig. 4a. It is seen that the anodic current density almost overlap for all scans. The cathodic current density below $0.6 \mathrm{~V}$ is larger for scans with higher upper potentials, suggesting that reduction of oxidative species or desorption of intermediate species is related to the upper potentials. As shown in Fig. S1, the deactivation as a function of cycle numbers was very obvious if the upper potential was higher than peak potential $(>-0.1 \mathrm{~V})$, and this deactivation increased with the upper potential limit. In contrast, when $-0.2 \mathrm{~V}$ was used as the upper potential limit, there was almost no deactivation after $10 \mathrm{CV}$ cycles. One deactivation cause is the formation of strongly adsorbed $\mathrm{N}_{\mathrm{ads}}$ that blocks the active sites. The deactivation rate caused by $\mathrm{N}_{\mathrm{ads}}$ is expected to be proportional to the number of $\mathrm{N}_{\text {ads }}$ species, which should be related to the total charge consumed in AOR. However, as can be seen in Fig. 4a and Fig. S1, the total charge consumed at higher 
upper potential limits are not significantly higher than that at lower upper potential limits (due to rapid drop in current density above $-0.1 \mathrm{~V}$ ), which means that $\mathrm{N}_{\mathrm{ads}}$ is probably not the solely dominant poisonous species at potentials above $-0.1 \mathrm{~V}$. Probable candidate poisonous species include $\mathrm{OH}_{\text {ads }}$ and surface oxide, as it has been reported that $\mathrm{OH}$ has a higher adsorption energy on $\mathrm{Pt}$ than $\mathrm{NH}_{3}$.[39] Several research groups have reported that the presence of $\mathrm{OH}_{\mathrm{ads}}$ and chemisorbed surface oxide can greatly hinder electrocatalytic reactions, like oxygen reduction reaction.[40-42] As the potential increases, hydroxide ions starts to adsorb on Pt surface in alkaline solution at around $0.5 \mathrm{~V}$ vs. RHE (-0.326 V vs. SHE) and surface coverage of $\mathrm{OH}_{\mathrm{ads}}$ increases significantly. Above $0.8 \mathrm{~V}$ vs. RHE (-0.026 V vs SHE), Pt surface begins to form a thin oxide film.[41] These results are consistent with our experimental observation and suggest that $\mathrm{OH}_{\text {ads }}$ and surface oxide could be the major cause of deactivation for AOR at potential >-0.15 V vs. SHE. To further validate our assumption, Pt/C catalyst was pre-oxidized at $0.2 \mathrm{~V}$ vs. SHE for $1 \mathrm{~min}$ in $1 \mathrm{M} \mathrm{KOH}$ and then this oxidized Pt/C catalyst was used for $\mathrm{CV}$ scan between $-0.3 \mathrm{~V}$ and $0.2 \mathrm{~V}$ in $1 \mathrm{M} \mathrm{KOH}$ and $1 \mathrm{M} \mathrm{NH}_{3}$. As can be seen in Fig. $4 \mathrm{~b}$, the oxidized $\mathrm{Pt} / \mathrm{C}$ only exhibited a very small ammonia oxidation peak around $-0.06 \mathrm{~V}$, which can be attributed to ammonia oxidation into $\mathrm{NO}_{\mathrm{x}}$ on oxidized Pt.[19, 43] A similar peak is also observed for fresh $\mathrm{Pt} / \mathrm{C}$ electrode above $0 \mathrm{~V}$. The electrode can be fully recovered after the oxidized $\mathrm{Pt} / \mathrm{C}$ electrode is reduced at $-0.8 \mathrm{~V}$ for $1 \mathrm{~min}$, indicating a reversible poisoning effect of $\mathrm{O} / \mathrm{OH}_{\mathrm{ads}}$. Thus, the practical operating voltage of ammonia electrolyzers or fuel cells should be carefully examined because of the detrimental effect of $\mathrm{O} / \mathrm{OH}_{\mathrm{ads}}$ species on $\mathrm{AOR}$.

To study the poisoning effect of $\mathrm{N}_{\mathrm{ads}}$, AOR was tested by $\mathrm{CV}$ using an upper potential limit of $-0.25 \mathrm{~V}$ to prevent poisoning from $\mathrm{O} / \mathrm{OH}_{\mathrm{ads}}$. The first-cycle $\mathrm{CV}$ curves (Fig. 4c) are almost identical in the region above $-0.5 \mathrm{~V}$. However, as shown in Fig. S2, AOR still suffered slightly 
from deactivation as a function of cycle numbers. Since the influence of $\mathrm{O} / \mathrm{OH}_{\mathrm{ads}}$ can be excluded, this deactivation can be ascribed to strongly adsorbed $\mathrm{N}_{\text {ads }}$ atoms. Closer examination of cathodic scan of Pt/C (Fig. 4d) in $1 \mathrm{M} \mathrm{KOH}$ and $1 \mathrm{M} \mathrm{NH}_{3}$ solution scanned between $-0.8 \mathrm{~V}$ and $-0.25 \mathrm{~V}$ displays that the $\mathrm{H}_{\text {ads }}$ peak decreases with cycle number. The suppression of hydrogen adsorption peak is likely because of blocking Pt surface by $\mathrm{N}_{\text {ads. }}$. This assumption is supported by the fact that $\mathrm{N}_{\text {ads }}$ atom binds more strongly on Pt than $\mathrm{H}_{\text {ads. }}[19,44]$ In addition, there is an increase in the cathodic current below $-0.65 \mathrm{~V}$ vs. SHE, probably due to the reduction of $\mathrm{N}_{\mathrm{ads}}$ from the Pt surface. These results indicate that the oxidative adsorbates from AOR, most likely $\mathrm{N}_{\mathrm{ads}}$, are the major cause of poisoning. To quantify the rate of poisoning, ammonia oxidation was carried out on Pt/C at $-0.25 \mathrm{~V}$ vs. SHE for different time. Then, the cathodic scan from $-0.5 \mathrm{~V}$ to $-0.8 \mathrm{~V}$ vs. SHE was performed and shown in Fig. 4e. With the increase in reaction time, the hydrogen adsorption peak gradually declines and the charge required to remove $\mathrm{N}_{\mathrm{ads}}$ raises. The surface coverage of $\mathrm{N}_{\mathrm{ads}}$ as a function of reaction time can be estimated by Eq. 2 .

$$
\theta_{\mathrm{N}_{\mathrm{ads}}}=1-\frac{\mathrm{q}_{\mathrm{H}_{\text {ads }}}}{\mathrm{q}_{\mathrm{H}_{\mathrm{ads}, 0}}}
$$

The charge of hydrogen adsorption peak $\left(\mathrm{H}_{\mathrm{ads}}\right)$ and surface coverage of $\mathrm{N}_{\mathrm{ads}}$ versus reaction time is shown in Fig. $4 \mathrm{f}$. It can be seen that after 30 min of reaction at $-0.25 \mathrm{~V}$ almost $90 \%$ of the catalyst surface was covered by $\mathrm{N}_{\mathrm{ads}}$. Interestingly, the plot of charge of $\mathrm{H}_{\mathrm{ads}}$ possesses very similar decay trend with the chronoamperometric curve (Fig. S3a), suggesting that $\mathrm{N}_{\mathrm{ads}}$ is the dominant factor for catalyst degradation during chronoamperometric tests at $-0.25 \mathrm{~V}$. The coulombic efficiency of forming $\mathrm{N}_{\mathrm{ads}}$ can be calculated based on normalization of the charge to remove $\mathrm{N}_{\mathrm{ads}}$ by the total charge of AOR and shown in Fig. S3b. It is shown that the coulombic efficiency of forming $\mathrm{N}_{\mathrm{ads}}$ is initially about $1 \%$ (30 s reaction time) and gradually decreases to 
$0.36 \%$ (1800 s reaction time). Considering the fact that AOR was only carried out for less than half an hour, this rate of poisoning is quite significant. It is, thus, not surprising $\mathrm{Pt} / \mathrm{C}$ exhibited very rapid degradation within a few minutes during chronoamperometry tests for ammonia oxidation.[31] A catalyst with lower $\mathrm{N}_{\mathrm{ads}}$ binding energy is expected to have lower formation rate of passive $\mathrm{N}_{\mathrm{ads}}$ and faster dimerization reaction between two $\mathrm{N}$ atoms. Nevertheless, designing such a catalyst remains a challenge, because lowering $\mathrm{N}_{\text {ads }}$ binding energy also results in lower $\mathrm{NH}_{\mathrm{x}}$ binding energy, which may be detrimental to dimerization of $\mathrm{NH}_{\mathrm{x}}$ species. Revising AOR by different Pt alloy catalysts is highly desirable to unveil the correlation between the binding energy of intermediate species and the rate of poisoning.

Insert Fig. 4.

Fig. 5a shows the cyclic voltammograms of ammonia oxidation by Pt/C catalyst in $1 \mathrm{M}$ $\mathrm{KOH}$ and $1 \mathrm{M} \mathrm{NH}_{3}$ at different scan rates. The current density increased with scan rate and the peak current density was linearly proportional to the square root of the scan rates (Fig. 4b), which suggests that AOR follows a diffusion-controlled mechanism.[45] The Tafel analysis is a powerful tool to discover the rate determining steps involved in an electrochemical reaction. Tafel analysis is performed by plotting the potential vs. the log of kinetic current density $\left(\mathrm{i}_{\mathrm{k}}\right)$. Because the diffusion-limiting current density is at least one order higher than what have been observed in our experiments,[31] the measured current density is in close proximity to be used directly as $\mathrm{i}_{\mathrm{k}}$. Typical Tafel plots of Pt/C catalyst at different scan rates are shown in Fig. 5b. A Tafel slope around $30 \mathrm{mV} \mathrm{dec}{ }^{-1}$ is observed for all scan rates. This result suggests that the dimerization of $\mathrm{NH}_{2}$ species can be the rate-determining step and AOR dominantly takes place 
on $\operatorname{Pt}(100)$ plane.[25] As reported in the literature, Tafel slope can also be obtained by analysis of a plot of the peak potential $\left(E_{p}\right)$ vs. the logarithm of the scan rate.[25] However, instead of one linear relationship, two linear regions are observed and shown in Fig. S4. The contradictory result in Fig. S4 is probably because $\mathrm{E}_{\mathrm{p}}$ is not only affected by AOR kinetics, but also by surface coverage of $\mathrm{OH} / \mathrm{O}_{\mathrm{ads}}$ and $\mathrm{N}_{\mathrm{ads}}$, mass transport, etc.

\section{Insert Fig. 5.}

Fig. 6 shows the anodic and cathodic portions of the cyclic voltammograms measured on Pt in $1 \mathrm{M} \mathrm{KOH}$ solution with the various ammonia concentrations. All these solutions have almost the same $\mathrm{pH}$ (measured to be about 14), because $\mathrm{NH}_{3}$ is a weak base. As can be seen in Fig. 6a, the AOR peak current density increases with the $\mathrm{NH}_{3}$ concentration. Plot of current density as a function of $\mathrm{NH}_{3}$ concentration (Fig. 6b) reveals that the current density increases linearly at low $\mathrm{NH}_{3}$ concentrations $\left(1 \mathrm{mM}\right.$ to $10 \mathrm{mM}$ ) and then begins to level off at higher $\mathrm{NH}_{3}$ concentrations. At low $\mathrm{NH}_{3}$ concentrations, the reaction is governed majorly by ammonia diffusion, while at higher $\mathrm{NH}_{3}$ concentration the reaction is also limited by the reaction kinetics, diffusion of reaction products, local $\mathrm{pH}$ change, as well as possible surface poisoning by $\mathrm{N}_{\mathrm{ads}}$. One would expect that the thermodynamic voltage of AOR should be dependent on the concentration of the reactants according to Nernst equation,

$$
\mathrm{E}=\mathrm{E}_{0}-2.303 \frac{\mathrm{RT}}{3 \mathrm{~F}} \log \frac{\left[\mathrm{NH}_{3}\right]\left[\mathrm{OH}^{-}\right]^{3}}{\left[\mathrm{~N}_{2}\right]^{1 / 2}}
$$

where $\mathrm{E}$ is the equilibrium potential, $\mathrm{E}_{0}$ the standard equilibrium potential, $\mathrm{R}$ the universal gas constant $\left(8.314 \mathrm{Jmol}^{-1} \mathrm{~K}^{-1}\right)$, T the temperature (in K), F the Faraday constant $\left(96485 \underline{\mathrm{C}} \mathrm{mol}^{-1}\right)$. However, it is surprising that the $\mathrm{CV}$ curves of $\mathrm{NH}_{3}$ concentration above $5 \mathrm{mM}$ overlapped in the 
voltage region above $-0.3 \mathrm{~V}$. This again suggests that $\mathrm{AOR}$ in the relatively large overpotential region is governed not only by the ammonia diffusion but also by other factors, like reaction kinetics, diffusion of hydroxide and reaction products, as well as possible surface poisoning. Closer examination of the region between $-0.8 \mathrm{~V}$ vs. $-0.3 \mathrm{~V}$ (Fig. 6c) reveals that the hydrogen desorption peak and onset potential of AOR shift to lower potential with increase in ammonia concentration. The negative shift in hydrogen desorption peak indicates the decrease in hydrogen binding energy (HBE) with increase in ammonia concentration.[35, 46] Plot of hydrogen desorption peak for $\mathrm{Pt}(100)$ as a function of $\log \left[\mathrm{NH}_{3}\right]$ shows a linear correlation with a slope of about $-26 \mathrm{mV} \mathrm{dec}-1$. It is worth noting that this slope is steeper than literature reported slopes of $12 \mathrm{mV}$ per $\mathrm{pH}$ for peak shift as a function of $\mathrm{pH}$ change,[35] suggesting that ammonia has a significant role in changing the HBE. Interestingly, the slope for onset potential of AOR vs. $\log \left[\mathrm{NH}_{3}\right]$ was determined to be about $-22.6 \mathrm{mV} \mathrm{dec}^{-1}$, which is very close to the theoretical value $\left(-2.303 \mathrm{RT} / 3 \mathrm{~F}=-19.7 \mathrm{mV} \mathrm{dec}{ }^{-1}\right)$ according to Eq. 3. In addition, it may be hypothesized that there is a correlation between onset potential of AOR and the HBE, because AOR seems to take place only after hydrogen atoms desorb from the Pt surface.

Insert Fig. 6.

The effect of $\mathrm{pH}$ on AOR by Pt/C catalyst was determined by conducting the experiments in $1 \mathrm{M} \mathrm{NH}_{3}$ with different $\mathrm{KOH}$ concentrations, and cyclic voltammograms are shown in Fig. 7. It can be observed that with the increase in $\mathrm{pH}$ (i.e. $\mathrm{KOH}$ concentration) the AOR peak current density increases significantly and also the ammonia oxidation peak shifts negatively. The addition of hydroxide ions can not only promote the reaction rate of ammonia oxidation, but also 
causes a negative shift in the thermodynamic potential. According to Nernst equation (Eq. 3), the AOR potential should shift negatively by ca. $59.2 \mathrm{mV}$ per $\mathrm{pH}$ increase. Fig. $7 \mathrm{c}$ shows that the onset potential and pre-peak potential shift negatively at a slope of about $60 \mathrm{mV} \mathrm{pH}^{-1}$, which is consistent with our prediction. However, the peak potential exhibits a non-Nernstian dependence of $\mathrm{pH}$ with a slope of about $83 \mathrm{mV} \mathrm{pH}^{-1}$, suggesting a complicated role of $\mathrm{pH}$ on AOR. Katsounaros et al. has recently reported a similar non-Nernstian slope of about $90-100 \mathrm{mV}$ per $\mathrm{pH}$, and this non-Nernstian slope has been attributed to a change of the local $\mathrm{pH}$ at the solid-liquid interface.[37] Furthermore, it is striking that this non-Nernstian slope is not a constant, but strongly dependent on the applied overpotential. The potential at different current densities as a function of $\mathrm{pH}$ is shown in Fig. $7 \mathrm{~d}$. It can be seen that the slope increases with the current density. For instance, the peak shifts per $\mathrm{pH}$ at $0.05,0.1,0.2,0.3$, and $0.5 \mathrm{~mA} \mathrm{~cm}^{-2}$ are 65.6, 75.1, 83, 82.7, 98.1 $\mathrm{mV}$ per $\mathrm{pH}$ change, respectively. The local $\mathrm{pH}$ is strongly dependent on the current density.[47] At low current densities, the local $\mathrm{pH}$ is only slightly altered because a small amount of hydroxide is consumed. In contrast, at high current densities the depletion of hydroxide ions can lead to significant drop in local $\mathrm{pH}$ near the solid-liquid interface. These results suggest that the non-Nernstian slope is very likely correlated to the local $\mathrm{pH}$. The peak potential only shifted negatively by $83 \mathrm{mV}$ per $\mathrm{pH}$, possible due to the influence of mass transport, surface coverage of $\mathrm{OH}^{-}$, and poisonous $\mathrm{N}_{\text {ads }}$ species. Although exact causes of this non-Nernstian slope cannot be elucidated in this work, the complicated role of $\mathrm{pH}$ (i.e. $\mathrm{OH}^{-}$), particularly local $\mathrm{pH}$ near active sites, needs to be taken into consideration in future studies.

Insert Fig. 7. 
Cyclic voltammograms of $\mathrm{Pt} / \mathrm{C}$ catalyst in $\mathrm{N}_{2}$-saturated $1 \mathrm{M} \mathrm{KOH}$ and $1 \mathrm{M} \mathrm{NH}_{3}$ solution at different rotating rates are shown in Fig. 8a. The AOR peak appears at around $-0.15 \mathrm{~V}$ for all rotation rates, and all CV curves are almost identical. Magnified view of AOR peak reveals that the peak current density first increases with rotating rate, peaks at $800 \mathrm{rpm}$, then decreases. This result is quite striking, considering that stationary-electrode voltammetry (Fig. 5a) shows AOR is diffusion controlled. The initial increase with rotating rate is likely due to improved mass transport. When the rotating rate further increases, some weakly bonded intermediates products (i.e. $\mathrm{N}_{2} \mathrm{H}_{4}$, etc.) during ammonia oxidation may escape from the Pt surface and cannot be further oxidized, leading to loss in current density. However, it is worth noting that the deviation in current density at different rotating rates is small (within 10\%). This phenomenon illustrates that AOR is a complex electrochemical process, controlled by multi-step electron transfer, multi-path reaction kinetics, and mass transport of different species. The nature of these intermediate species and their adsorption strength is still unknown. A through study including identification of intermediate species via in-situ mass spectroscopy technique combined with computational calculations could unveil further details on the nature of these intermediates and their role on AOR.

Insert Fig. 8

\subsection{Electrochemical oxidation of ammonia on Ir/C electrode}

Ir has been reported as the second best catalyst for AOR, and has been extensively studied as catalyst alone or alloying with Pt.[5, 19, 48] The electrochemical performance of AOR by Ir/C electrode was evaluated by $\mathrm{CV}$ scan in $1 \mathrm{M} \mathrm{KOH}$ in the presence and absence of $1 \mathrm{M} \mathrm{NH}_{3}$ at 
room temperature and corresponding CV curves are shown in Fig. 9. As can be seen in Fig. 9a, the hydrogen adsorption/desorption peak shifts to a lower potential (at around -0.7 V vs. SHE), suggesting that the presence of ammonia/ammonium ions can also influence the hydrogen binding energy of Ir and consequently hydrogen adsorption/desorption potential. The onset potential of AOR is around $-0.53 \mathrm{~V}$ vs. SHE, suggesting a lower overpotential $(240 \mathrm{mV})$ for AOR on Ir than Pt $(310 \mathrm{mV})$. It is worth noting that the PZC of Ir is about $100 \mathrm{mV}$ lower than that of Pt, which is consistent with the difference of onset potential for AOR.[49] The PZC is related to the hydrogen adsorption/desorption behavior. Typically, hydrogen adsorption/desorption occurs below the PZC.[35] The HBE of Ir is lower than that of Pt, therefore, the onset potential of AOR for Ir/C catalyst is also more negative than that for $\mathrm{Pt} / \mathrm{C}$. These findings underline that the onset potential of AOR is strongly dependent on the HBE of a catalyst. The AOR on Ir/C peaked at about $-0.22 \mathrm{~V}$ with a current density of only about $1 \mathrm{~mA}$ $\mathrm{cm}^{-2}$, much lower than that for Pt/C. This probably is caused by the poor kinetics and larger binding energy of $\mathrm{N}_{\text {ads }}$ on Ir.[19] Unlike Pt/C, there is no pre-peak present prior to the main AOR peak. The absence of this pre-peak may suggest that the adsorption of ammonia on Ir is masked by the ammonia oxidation that occurs at an earlier on set potential than on $\mathrm{Pt} / \mathrm{C}$ or that the prepeak observed on Pt/C may not be attributed to ammonia adsorption. This is an interesting finding that should be carefully studied in the future, as it may lead to better understanding on kinetics processes of AOR. Similar to $\mathrm{Pt} / \mathrm{C}, \mathrm{Ir} / \mathrm{C}$ also suffers from severe performance loss upon $\mathrm{CV}$ cycling. The same recovering procedure was used for $\mathrm{Ir} / \mathrm{C}$, however, the catalyst could not be successfully recovered, as illustrated in Fig. 9b. When the electrode was reduced at -0.9 V vs. SHE, even formation of bubbles were observed due to hydrogen evolution reaction. In contrast to Pt catalyst, the deactivation of Ir catalyst is irreversible. In addition, there is a dramatic decrease 
in hydrogen desorption peak, possibly due to either surface poisoning or loss of ECSA.

Insert Fig. 9.

To investigate the origin of the irreversible deactivation of Ir/C catalyst, cyclic voltammograms of $\mathrm{Ir} / \mathrm{C}$ in $1 \mathrm{M}$ ammonia and $1 \mathrm{M} \mathrm{KOH}$ solution with a constant lower potential limit of $-0.8 \mathrm{~V}$ and various upper switch potentials were measured and shown in Fig. 10a and Fig. S5. It is necessary to use a fresh electrode for each electrochemical test, because the catalyst cannot be recovered. It is shown in Fig. 10a that the anodic current density almost overlap for all first-cycle scans. However, the deactivation as a function of cycle numbers is very obvious if the upper potential is higher than peak potential of $-0.2 \mathrm{~V}$ vs. SHE, and this deactivation increases with the upper potential limit (Fig. S5). In contrast, when $-0.3 \mathrm{~V}$ vs. SHE is used as the upper potential limit, there is only minor deactivation. Similar to $\mathrm{Pt}$, the major poisonous species at high potentials are likely $\mathrm{OH}_{\text {ads }}$ and surface oxides. As the potential increases, hydroxide ions started to adsorb on Ir surface at around $0.4 \mathrm{~V}$ vs. RHE (-0.426 V vs. SHE) and Ir is oxidized into $\operatorname{Ir}(\mathrm{OH})_{3}$. Above the potential raised above $0.77 \mathrm{~V}$ vs. RHE (-0.056 V vs SHE), $\operatorname{Ir}(\mathrm{OH})_{3}$ can further be oxidized into anhydrous $\mathrm{IrO}_{2}$.[50] The hydrogen adsorption/desorption peak declines due to the irreversible loss of ECSA. These findings are consistent with our experimental results, as $\mathrm{Ir}$ can go through an irreversible phase change to form $\operatorname{Ir}(\mathrm{OH})_{3}$ and $\mathrm{IrO}_{2}$ at higher potentials. To further validate our assumption, the Ir/C catalyst was pre-oxidized at $0.2 \mathrm{~V}$ vs. SHE for 1 min in $1 \mathrm{M} \mathrm{KOH}$ and subject to $\mathrm{CV}$ scan between $-0.3 \mathrm{~V}$ and $0.2 \mathrm{~V}$ in $1 \mathrm{M} \mathrm{KOH}$ and $1 \mathrm{M} \mathrm{NH}_{3}$. As can be seen in Fig. 10b, the oxidized Pt/C exhibits a very small activity toward ammonia oxidation. Even after the pre-oxidized electrode was reduced at $-0.9 \mathrm{~V}$ for $1 \mathrm{~min}$, its AOR 
activity still could not be fully recovered. Although Ir exhibits lower overpotential than Pt, it suffers from many disadvantages, i.e. slow AOR kinetics, larger strong binding energy of $\mathrm{N}_{\mathrm{ads}}$, severe deactivation due to irreversible phase change. To avoid irreversible losses of Ir catalyst performance, potentials more positive than -0.2 vs. SHE should not be applied. This consideration is important for the operation of ammonia electrolysis, fuel cells, and sensors.

Insert Fig. 10.

\subsection{Electrochemical oxidation of ammonia on $\mathrm{Rh} / \mathrm{C}$ electrode}

As reported previously, 4d transition metals, such as rhodium, ruthenium, and palladium exhibited negligible AOR activity.[19] In this work, $\mathrm{Rh} / \mathrm{C}$ catalyst was chosen to revisit its AOR performance, because it has shown excellent performance when alloying with Pt.[8] Fig. 11 shows typical cyclic voltammograms of $\mathrm{Rh} / \mathrm{C}$ in $1 \mathrm{M} \mathrm{KOH}$ and $1 \mathrm{M} \mathrm{NH}_{3}$. Similar to $\mathrm{Pt} / \mathrm{C}$ and $\mathrm{Ir} / \mathrm{C}$, upon the addition of ammonia, the hydrogen adsorption/desorption peak for $\mathrm{Rh} / \mathrm{C}$ also shifts to a lower potential (at around $-0.6 \mathrm{~V}$ vs. SHE). Interestingly, a small shoulder peak around $-0.52 \mathrm{~V}$ is present (indicated in Fig. 11 by a black arrow) after hydrogen desorption peak and a much higher peak around $-0.6 \mathrm{~V}$ can be found, which may be due to ammonia oxidation on Rh.[19] The HBE of $\mathrm{Rh}$ is much lower than that of $\mathrm{Pt},[35]$ thus, the oxidation of ammonia may occur much earlier on Rh $(-0 . \underline{6} \mathrm{~V})$ than on $\mathrm{Pt}(-0.46 \mathrm{~V})$. However, as reported in the literature, no steady-state production of $\mathrm{N}_{2}$ has been found for Rh catalyst,[19] consistent with our observation of very low activity. Based on computational calculations, it was suggested by de Vooys et al. that $\mathrm{NH}_{3}$ can rapidly be dehydrogenated to $\mathrm{N}_{\mathrm{ads}}$, suppressing further reaction.[19] A pre-peak that has been reported to be related to ammonia adsorption of Pt/C catalysts is not observed, indicating a weaker adsorption of ammonia. Therefore, one could hypothesize that the weak 
adsorption of ammonia and strong adsorption of $\mathrm{N}_{\mathrm{ads}}$ atoms on $\mathrm{Rh}$ lead to minimum ammonia electrooxidation. Although $\mathrm{Rh}$ has remarkably slow reaction rate of AOR,[51] it suffers less from degradation, as indicated by the overlapping $\mathrm{CV}$ curves over several cycles.

Insert Fig. 11.

\section{Conclusion}

In this work, we have revisited the electrochemical oxidation of ammonia in alkaline solution on a series of carbon supported nanoparticle catalysts, such as $\mathrm{Pt} / \mathrm{C}$, Ir/C, and $\mathrm{Rh} / \mathrm{C}$. The electrochemical performance was revealed by carefully treating the electrode prior to each electrochemical measurement. The $\mathrm{Pt} / \mathrm{C}$ catalyst possessed the highest electrocatalytic activity, while $\mathrm{Ir} / \mathrm{C}$ and $\mathrm{Rh} / \mathrm{C}$ had lower overpotential for AOR. The onset potential of AOR was found to be related to the HBE. $\mathrm{N}_{\mathrm{ads}}$ is one major deactivation cause. In addition, the formation of surface $\mathrm{O} / \mathrm{OH}_{\mathrm{ads}}$ at high potentials can significantly inhibit the reaction. The poisoning due to $\mathrm{O} / \mathrm{OH}_{\mathrm{ads}}$ on Pt is reversible and can be recovered, while the oxidation of Ir undergoes an irreversible phase change. Due to strong binding energy of $\mathrm{N}_{\mathrm{ads}}$ on Pt, the coulombic efficiency of poisonous $\mathrm{N}_{\mathrm{ads}}$ was about $1 \%$. AOR is a diffusion-controlled process and has a Tafel slope of about $30 \mathrm{mV} \mathrm{dec}^{-}$ 1 , indicating the dimerization of $\mathrm{NH}_{2}$ species as the rate-determining step. Increase in ammonia concentration only lead to increase in peak current density, but not a significant shift in the potential. Increase in $\mathrm{KOH}$ concentration (i.e. $\mathrm{pH}$ ) can enhance the peak current density and reduce the overpotential simultaneously. The $\mathrm{pH}$ dependence of AOR onset potential for $\mathrm{Pt} / \mathrm{C}$ catalyst follows Nernst equation. In contrast, non-Nernstian slopes are observed for potentials measured at different current densities, suggesting a critical role of the local $\mathrm{pH}$ change. In 
summary, although promising, electro-oxidation of ammonia on monometallic PGMs suffers from sluggish kinetics, deactivation due to strong adsorption of poisonous species (i.e. $\mathrm{N}_{\mathrm{ads}}$, $\left.\mathrm{O} / \mathrm{OH}_{\mathrm{ads}}\right)$. Future work needs to be done to revisit Pt alloy catalysts to unveil the correlation between binding energy of different intermediates and electrocatalytic activity as well as the rate of poisoning. A through study including identification of adsorbate species via in-situ spectroscopy techniques combined with computational calculations and mathematical modeling could unveil further details on the mechanism of the reaction. However, the important experimental considerations reported in this study should be maintained to guarantee the reliability of the electrochemical measurements.

\section{Acknowledgements}

The authors would like to thank the financial support from the Center for Electrochemical Engineering Research (CEER) at Ohio University and the National Science Foundation through the Major Research Instrumentation Grant \# CBET-1126350. 


\section{References}

[1] C. Zamfirescu, I. Dincer, Using ammonia as a sustainable fuel, Journal of Power Sources, 185 (2008) 459-465.

[2] W. Wang, J.M. Herreros, A. Tsolakis, A.P.E. York, Ammonia as hydrogen carrier for transportation; investigation of the ammonia exhaust gas fuel reforming, International Journal of Hydrogen Energy, 38 (2013) 9907-9917.

[3] E.J. Cairns, E.L. Simons, A.D. Tevebaugh, Ammonia-Oxygen Fuel Cell, Nature, 217 (1968) $780-781$.

[4] E.L. Simons, E.J. Cairns, D.J. Surd, The Performance of Direct Ammonia Fuel Cells, Journal of The Electrochemical Society, 116 (1969) 556-561.

[5] F.J. Vidal-Iglesias, J. Solla-Gullón, V. Montiel, J.M. Feliu, A. Aldaz, Screening of electrocatalysts for direct ammonia fuel cell: Ammonia oxidation on PtMe (Me: Ir, Rh, Pd, Ru) and preferentially oriented Pt(1 0 0) nanoparticles, Journal of Power Sources, 171 (2007) 448456.

[6] S. Suzuki, H. Muroyama, T. Matsui, K. Eguchi, Fundamental studies on direct ammonia fuel cell employing anion exchange membrane, Journal of Power Sources, 208 (2012) 257-262.

[7] M.H.M.T. Assumpção, S.G. da Silva, R.F.B. de Souza, G.S. Buzzo, E.V. Spinacé, A.O. Neto, J.C.M. Silva, Direct ammonia fuel cell performance using PtIr/C as anode electrocatalysts, International Journal of Hydrogen Energy, 39 (2014) 5148-5152.

[8] M. Cooper, G.G. Botte, Hydrogen Production from the Electro-oxidation of Ammonia Catalyzed by Platinum and Rhodium on Raney Nickel Substrate, Journal of The Electrochemical Society, 153 (2006) A1894-A1901.

[9] F. Vitse, M. Cooper, G.G. Botte, On the use of ammonia electrolysis for hydrogen 
production, Journal of Power Sources, 142 (2005) 18-26.

[10] B.K. Boggs, G.G. Botte, On-board hydrogen storage and production: An application of ammonia electrolysis, Journal of Power Sources, 192 (2009) 573-581.

[11] L. Marinčić, F.B. Leitz, Electro-oxidation of ammonia in waste water, Journal of Applied Electrochemistry, 8 (1978) 333-345.

[12] E.P. Bonnin, E.J. Biddinger, G.G. Botte, Effect of catalyst on electrolysis of ammonia effluents, Journal of Power Sources, 182 (2008) 284-290.

[13] A. Kapałka, S. Fierro, Z. Frontistis, A. Katsaounis, S. Neodo, O. Frey, N. de Rooij, K.M. Udert, C. Comninellis, Electrochemical oxidation of ammonia (NH4+/NH3) on thermally and electrochemically prepared IrO2 electrodes, Electrochimica Acta, 56 (2011) 1361-1365.

[14] H. Zöllig, C. Fritzsche, E. Morgenroth, K.M. Udert, Direct electrochemical oxidation of ammonia on graphite as a treatment option for stored source-separated urine, Water Research, 69 (2015) 284-294.

[15] L.A. Diaz, G.G. Botte, Hydrodynamic analysis and simulation of a flow cell ammonia electrolyzer, Electrochimica Acta, 179 (2015) 529-537.

[16] B.A.L. de Mishima, D. Lescano, T.M. Holgado, H.T. Mishima, Electrochemical oxidation of ammonia in alkaline solutions: its application to an amperometric sensor, Electrochimica Acta, 43 (1998) 395-404.

[17] X. Ji, C.E. Banks, R.G. Compton, The electrochemical oxidation of ammonia at borondoped diamond electrodes exhibits analytically useful signals in aqueous solutions, Analyst, 130 (2005) 1345-1347.

[18] J.F.E. Gootzen, A.H. Wonders, W. Visscher, R.A. van Santen, J.A.R. van Veen, A DEMS and cyclic voltammetry study of NH3 oxidation on platinized platinum, Electrochimica Acta, 43 
(1998) 1851-1861.

[19] A.C.A. de Vooys, M.T.M. Koper, R.A. van Santen, J.A.R. van Veen, The role of adsorbates in the electrochemical oxidation of ammonia on noble and transition metal electrodes, Journal of Electroanalytical Chemistry, 506 (2001) 127-137.

[20] L.A. Diaz, G.G. Botte, Mathematical modeling of ammonia electrooxidation kinetics in a Polycrystalline Pt rotating disk electrode, Electrochimica Acta, 179 (2015) 519-528.

[21] K. Endo, K. Nakamura, Y. Katayama, T. Miura, Pt-Me (Me = Ir, Ru, Ni) binary alloys as an ammonia oxidation anode, Electrochimica Acta, 49 (2004) 2503-2509.

[22] B.K. Boggs, G.G. Botte, Optimization of Pt-Ir on carbon fiber paper for the electrooxidation of ammonia in alkaline media, Electrochimica Acta, 55 (2010) 5287-5293.

[23] T.L. Lomocso, E.A. Baranova, Electrochemical oxidation of ammonia on carbon-supported bi-metallic PtM (M = Ir, Pd, SnOx) nanoparticles, Electrochimica Acta, 56 (2011) 8551-8558.

[24] F.J. Vidal-Iglesias, N. García-Aráez, V. Montiel, J.M. Feliu, A. Aldaz, Selective electrocatalysis of ammonia oxidation on $\operatorname{Pt}\left(\begin{array}{lll}1 & 0 & 0\end{array}\right)$ sites in alkaline medium, Electrochemistry Communications, 5 (2003) 22-26.

[25] V. Rosca, M.T.M. Koper, Electrocatalytic oxidation of ammonia on $\operatorname{Pt}(111)$ and $\operatorname{Pt}(100)$ surfaces, Physical Chemistry Chemical Physics, 8 (2006) 2513-2524.

[26] C. Zhang, S.Y. Hwang, Z. Peng, Shape-enhanced ammonia electro-oxidation property of a cubic platinum nanocrystal catalyst prepared by surfactant-free synthesis, Journal of Materials Chemistry A, 1 (2013) 14402-14408.

[27] Y. Katayama, T. Okanishi, H. Muroyama, T. Matsui, K. Eguchi, Electrochemical Oxidation of Ammonia over Rare Earth Oxide Modified Platinum Catalysts, The Journal of Physical Chemistry C, 119 (2015) 9134-9141. 
[28] J.C.M. Silva, R.M. Piasentin, E.V. Spinacé, A.O. Neto, E.A. Baranova, The effect of antimony-tin and indium-tin oxide supports on the catalytic activity of Pt nanoparticles for ammonia electro-oxidation, Materials Chemistry and Physics, 180 (2016) 97-103.

[29] H. Gerischer, A. Mauerer, Untersuchungen Zur anodischen Oxidation von Ammoniak an Platin-Elektroden, Journal of Electroanalytical Chemistry and Interfacial Electrochemistry, 25 (1970) 421-433.

[30] H.G. Oswin, M. Salomon, The anodic oxidation of ammonia at platinum black electrodes in aqueous KOH electrolyte, Canadian Journal of Chemistry, 41 (1963) 1686-1694.

[31] K. Endo, Y. Katayama, T. Miura, A rotating disk electrode study on the ammonia oxidation, Electrochimica Acta, 50 (2005) 2181-2185.

[32] E. Moran, C. Cattaneo, H. Mishima, B.A. López de Mishima, S.P. Silvetti, J.L. Rodriguez, E. Pastor, Ammonia oxidation on electrodeposited Pt-Ir alloys, Journal of Solid State Electrochemistry, 12 (2008) 583-589.

[33] A. Allagui, M. Oudah, X. Tuaev, S. Ntais, F. Almomani, E.A. Baranova, Ammonia electrooxidation on alloyed PtIr nanoparticles of well-defined size, International Journal of Hydrogen Energy, 38 (2013) 2455-2463.

[34] Z.-F. Li, L. Xin, F. Yang, Y. Liu, Y. Liu, H. Zhang, L. Stanciu, J. Xie, Hierarchical polybenzimidazole-grafted graphene hybrids as supports for Pt nanoparticle catalysts with excellent PEMFC performance, Nano Energy, 16 (2015) 281-292.

[35] J. Zheng, W. Sheng, Z. Zhuang, B. Xu, Y. Yan, Universal dependence of hydrogen oxidation and evolution reaction activity of platinum-group metals on $\mathrm{pH}$ and hydrogen binding energy, Science Advances, 2 (2016).

[36] E. Gileadi, S.D. Argade, J.O.M. Bockris, The Potential of Zero Charge of Platinum and Its 
pH Dependence, The Journal of Physical Chemistry, 70 (1966) 2044-2046.

[37] I. Katsounaros, T. Chen, A.A. Gewirth, N.M. Markovic, M.T.M. Koper, Evidence for Decoupled Electron and Proton Transfer in the Electrochemical Oxidation of Ammonia on Pt(100), The Journal of Physical Chemistry Letters, 7 (2016) 387-392.

[38] H. Zöllig, E. Morgenroth, K.M. Udert, Inhibition of Direct Electrolytic Ammonia Oxidation Due to a Change in Local pH, Electrochimica Acta, 165 (2015) 348-355.

[39] D.A. Daramola, G.G. Botte, Theoretical study of ammonia oxidation on platinum clusters Adsorption of ammonia and water fragments, Computational and Theoretical Chemistry, 989 (2012) 7-17.

[40] H. Tanaka, Y. Nagahara, S. Sugawara, K. Shinohara, M. Nakamura, N. Hoshi, The Influence of Pt Oxide Film on the Activity for the Oxygen Reduction Reaction on Pt Single Crystal Electrodes, Electrocatalysis, 5 (2014) 354-360.

[41] E.J. Coleman, M.H. Chowdhury, A.C. Co, Insights Into the Oxygen Reduction Reaction Activity of Pt/C and PtCu/C Catalysts, ACS Catalysis, 5 (2015) 1245-1253.

[42] E.J. Coleman, A.C. Co, The Complex Inhibiting Role of Surface Oxide in the Oxygen Reduction Reaction, ACS Catalysis, 5 (2015) 7299-7311.

[43] J.M. Bradley, A. Hopkinson, D.A. King, Control of a Biphasic Surface Reaction by Oxygen Coverage: The Catalytic Oxidation of Ammonia over Pt $\{100\}$, The Journal of Physical Chemistry, 99 (1995) 17032-17042.

[44] T.T.T. Hanh, Y. Takimoto, O. Sugino, First-principles thermodynamic description of hydrogen electroadsorption on the Pt(111) surface, Surface Science, 625 (2014) 104-111.

[45] L. Zhou, Y.F. Cheng, Catalytic electrolysis of ammonia on platinum in alkaline solution for hydrogen generation, International Journal of Hydrogen Energy, 33 (2008) 5897-5904. 
[46] R. Palaniappan, G.G. Botte, Effect of Ammonia on Pt, Ru, Rh, and Ni Cathodes During the Alkaline Hydrogen Evolution Reaction, The Journal of Physical Chemistry C, 117 (2013) 1742917441.

[47] I. Katsounaros, J.C. Meier, S.O. Klemm, A.A. Topalov, P.U. Biedermann, M. Auinger, K.J.J. Mayrhofer, The effective surface $\mathrm{pH}$ during reactions at the solid-liquid interface, Electrochemistry Communications, 13 (2011) 634-637.

[48] L. Cunci, C.V. Rao, C. Velez, Y. Ishikawa, C.R. Cabrera, Graphene-Supported Pt, Ir, and Pt-Ir Nanoparticles as Electrocatalysts for the Oxidation of Ammonia, Electrocatalysis, 4 (2013) 61-69.

[49] B.I. Podlovchenko, N.A. Epshtein, A.N. Frumkin, Investigation of the surface properties of platinum, rhodium and iridium electrodes in hydrofluoric acid solutions, Journal of Electroanalytical Chemistry and Interfacial Electrochemistry, 53 (1974) 95-104.

[50] T. Reier, M. Oezaslan, P. Strasser, Electrocatalytic Oxygen Evolution Reaction (OER) on Ru, Ir, and Pt Catalysts: A Comparative Study of Nanoparticles and Bulk Materials, ACS Catalysis, 2 (2012) 1765-1772.

[51] G. Papapolymerou, V. Bontozoglou, Decomposition of $\mathrm{NH}<\mathrm{sub}>3</ \mathrm{sub}>$ on $\mathrm{Pd}$ and $\mathrm{Ir}$ comparison with Pt, Journal of Molecular Catalysis. A, Chemical, 120 (1997) 165-171. 


\section{Figure Captions}

Fig. 1. TEM images and particle size histogram of (a) $\mathrm{Pt} / \mathrm{C}$, (b) $\mathrm{Ir} / \mathrm{C}$, and (c) $\mathrm{Rh} / \mathrm{C}$ catalysts. These catalysts possess uniform dispersion of metal nanoparticles on the carbon black support except that there is some aggregation for the $\mathrm{Rh} / \mathrm{C}$ catalyst.

Fig. 2. Cyclic voltammograms of $\mathrm{Pt} / \mathrm{C}$ (solid line) and $\mathrm{Rh} / \mathrm{C}$ (dotted line) in $0.1 \mathrm{M} \mathrm{HClO}_{4}$ and Ir/C (dashed line) in $0.05 \mathrm{M} \mathrm{H}_{2} \mathrm{SO}_{4}$ at a scan rate of $20 \mathrm{mV} \mathrm{s}^{-1}$. Hydrogen adsorption/desorption region is observed from 0.02 to $0.4 \mathrm{~V}$ vs. RHE. ECSA can be determined by measuring the integration of hydrogen adsorption-desorption area after double layer correction.

Fig. 3. $\mathrm{CV}$ curves of (a) $\mathrm{Pt} / \mathrm{C}$ catalyst in $1 \mathrm{M} \mathrm{KOH}$ in the presence and absence of $1 \mathrm{M} \mathrm{NH}_{3}$ at a scan rate of $20 \mathrm{mV} \mathrm{s}^{-1}$ and (b) fresh, deactivated, and recovered $\mathrm{Pt} / \mathrm{C}$ electrode in $1 \mathrm{M} \mathrm{KOH}$ and $1 \mathrm{M} \mathrm{NH}_{3}$ at a scan rate of $20 \mathrm{mV} \mathrm{s}^{-1}$. The onset potential of $\mathrm{Pt} / \mathrm{C}$ catalyst is around $-0.46 \mathrm{~V}$ vs. SHE and the peak potential about $-0.153 \mathrm{~V}$ vs. SHE. It is also observed that the $\mathrm{Pt} / \mathrm{C}$ catalyst degrades as a function of $\mathrm{CV}$ cycle number and can be recovered by cathodic reduction at $-0.8 \mathrm{~V}$ vs. SHE.

Fig. 4. Cyclic voltammograms measured on $\mathrm{Pt} / \mathrm{C}$ electrode in $1 \mathrm{M} \mathrm{KOH}$ and $1 \mathrm{M}$ ammonia solution (a) with a constant lower potential limit of $-0.8 \mathrm{~V}$ and various upper potential limits (1st cycle). (b) Cyclic voltammograms measured on fresh $\mathrm{Pt} / \mathrm{C}$ electrode, oxidized $\mathrm{Pt} / \mathrm{C}$ electrode, and oxidized $\mathrm{Pt} / \mathrm{C}$ electrode after reduction. (c) Cyclic voltammograms measured on $\mathrm{Pt} / \mathrm{C}$ electrode in $1 \mathrm{M} \mathrm{KOH}$ and $1 \mathrm{M}$ ammonia solution with a constant upper potential limit of -0.25 $\mathrm{V}$ and various lower potential limits (1st cycle). (d) $\mathrm{CV}$ curves of $\mathrm{Pt} / \mathrm{C}$ electrode $1 \mathrm{M} \mathrm{KOH}$ and 1 $\mathrm{M}$ ammonia solution scanned from $-0.8 \mathrm{~V}$ to $-0.25 \mathrm{~V}$ and from $-0.8 \mathrm{~V}$ to $-0.4 \mathrm{~V}$ vs. SHE. (e) Cathodic linear sweep measured on Pt/C electrode after holding in $1 \mathrm{M} \mathrm{KOH}$ and $1 \mathrm{M}$ ammonia solution at $-0.25 \mathrm{~V}$ vs. SHE for different time. (f) Integration of charge of hydrogen adsorption peak around $-0.58 \mathrm{~V}$ vs. SHE and calculated $\mathrm{N}_{\mathrm{ads}}$ surface coverage as a function of different 
reaction time at $-0.25 \mathrm{~V}$ vs. SHE. High surface coverage of $\mathrm{O} / \mathrm{OH}_{\text {ads }}$ above $-0.15 \mathrm{~V}$ vs. SHE was found to be the dominant factor for catalyst deactivation, while strongly adsorbed $\mathrm{N}_{\text {ads }}$ intermediates can also passivate the Pt surface.

Fig. 5. (a) $\mathrm{CV}$ curves of $\mathrm{Pt} / \mathrm{C}$ catalyst in $1 \mathrm{M} \mathrm{KOH}$ and $1 \mathrm{M} \mathrm{NH}_{3}$ at different scan rates. Insert: plot and fit of anodic peak current vs. $v^{1 / 2}$. (b) Tafel plots of Pt/C catalyst at different scan rates $\left(1,10,100 \mathrm{mV} \mathrm{s}^{-1}\right)$. The peak current density increased linearly with scan rate, indicating a diffusion-controlled mechanism for AOR. Tafel analysis shows a Tafel slope of $30 \mathrm{mV} \mathrm{dec}^{-1}$.

Fig. 6. (a) Representative $\mathrm{CV}$ curves of Pt/C catalyst in $1 \mathrm{M} \mathrm{KOH}$ with different concentrations of $\mathrm{NH}_{3}$. (b) Plot of anodic peak current density vs. $\mathrm{NH}_{3}$ concentration (insert: plot and fit of anodic peak current density vs. $\mathrm{NH}_{3}$ concentration at low $\mathrm{NH}_{3}$ concentrations). (c) Magnified $\mathrm{CV}$ curves of $\mathrm{Pt} / \mathrm{C}$ catalyst in $1 \mathrm{M} \mathrm{KOH}$ with different concentrations of $\mathrm{NH}_{3}$ between $-1 \mathrm{~V}$ and -0.2 V vs. SHE. (d) Plot and fit of hydrogen desorption peak and onset potential of AOR as a function of $\log \left[\mathrm{NH}_{3}\right]$. The peak current density increased linearly at low $\mathrm{NH}_{3}$ concentrations ( $1 \mathrm{mM}$ to 10 $\mathrm{mM}$ ) and then began to level off at higher $\mathrm{NH}_{3}$ concentrations. The addition of ammonia leads to negative shift in hydrogen desorption peak, i.e. reduction in HBE.

Fig. 7. (a) $\mathrm{CV}$ curves of $\mathrm{Pt} / \mathrm{C}$ catalyst in $1 \mathrm{M} \mathrm{NH}_{3}$ with different $\mathrm{KOH}$ concentrations. (b) Plot of anodic peak current density vs. $\mathrm{KOH}$ concentration and $\mathrm{pH}$. (c) Plot and fit of onset potential, pre-peak potential, and peak potential of AOR as a function of solution $\mathrm{pH}$. (d) Plot and fit of potential at different current densities as a function of solution $\mathrm{pH}$. Hydroxide ions not only can promote reaction rate of ammonia oxidation, but also cause a negative shift in the thermodynamic potential. The $\mathrm{pH}$ dependence of ammonia oxidation does not follow the Nernst equation.

Fig. 8. (a) Cyclic voltammograms of $\mathrm{Pt} / \mathrm{C}$ electrode in $\mathrm{N}_{2}$-purged $1 \mathrm{M} \mathrm{NH}_{3}$ and $1 \mathrm{M} \mathrm{KOH}$ 
solution at various rotation rates at a scan rate of $20 \mathrm{mV} \mathrm{s}^{-1}$. Insert: Magnified view of AOR peak. (b) Plot of peak current density as a functional of rotation rate. The peak current density first increases then decreases with rotating rate.

Fig. 9. $\mathrm{CV}$ curves of (a) $\mathrm{Ir} / \mathrm{C}$ catalyst in $1 \mathrm{M} \mathrm{KOH}$ in the presence and absence of $1 \mathrm{M} \mathrm{NH}_{3}$ at a scan rate of $20 \mathrm{mV} \mathrm{s}^{-1}$ and (b) fresh, deactivated, and recovered $\mathrm{Ir} / \mathrm{C}$ electrode in $1 \mathrm{M} \mathrm{KOH}$ and 1 $\mathrm{M} \mathrm{NH}_{3}$ at a scan rate of $20 \mathrm{mV} \mathrm{s}^{-1}$. Ir/C catalyst has lower activity than $\mathrm{Pt} / \mathrm{C}$ and suffers from irreversible degradation over several CV cycles.

Fig. 10. Cyclic voltammograms measured on $\mathrm{Ir} / \mathrm{C}$ electrode in $1 \mathrm{M} \mathrm{KOH}$ and $1 \mathrm{M}$ ammonia solution (a) with a constant lower potential limit of $-0.8 \mathrm{~V}$ and various upper potential limits (1st cycle). (b) Cyclic voltammograms measured on fresh Ir/C electrode, oxidized Ir/C electrode, and oxidized Ir/C electrode after reduction. Irreversible formation of $\operatorname{Ir}(\mathrm{OH})_{3}$ and $\mathrm{IrO}_{2}$ was found to be the dominant factor for catalyst deactivation at potential $>-0.2 \mathrm{~V}$ vs. SHE.

Fig. 11. $\mathrm{CV}$ curves of $\mathrm{Rh} / \mathrm{C}$ catalyst in $1 \mathrm{M} \mathrm{KOH}$ in the presence and absence of $1 \mathrm{M} \mathrm{NH}_{3}$ at a scan rate of $20 \mathrm{mV} \mathrm{s}^{-1}$. A shoulder peak after hydrogen desorption peak at $-0.6 \mathrm{~V}$ is indicated by a black arrow, which may be attributed to ammonia oxidation on Rh. 


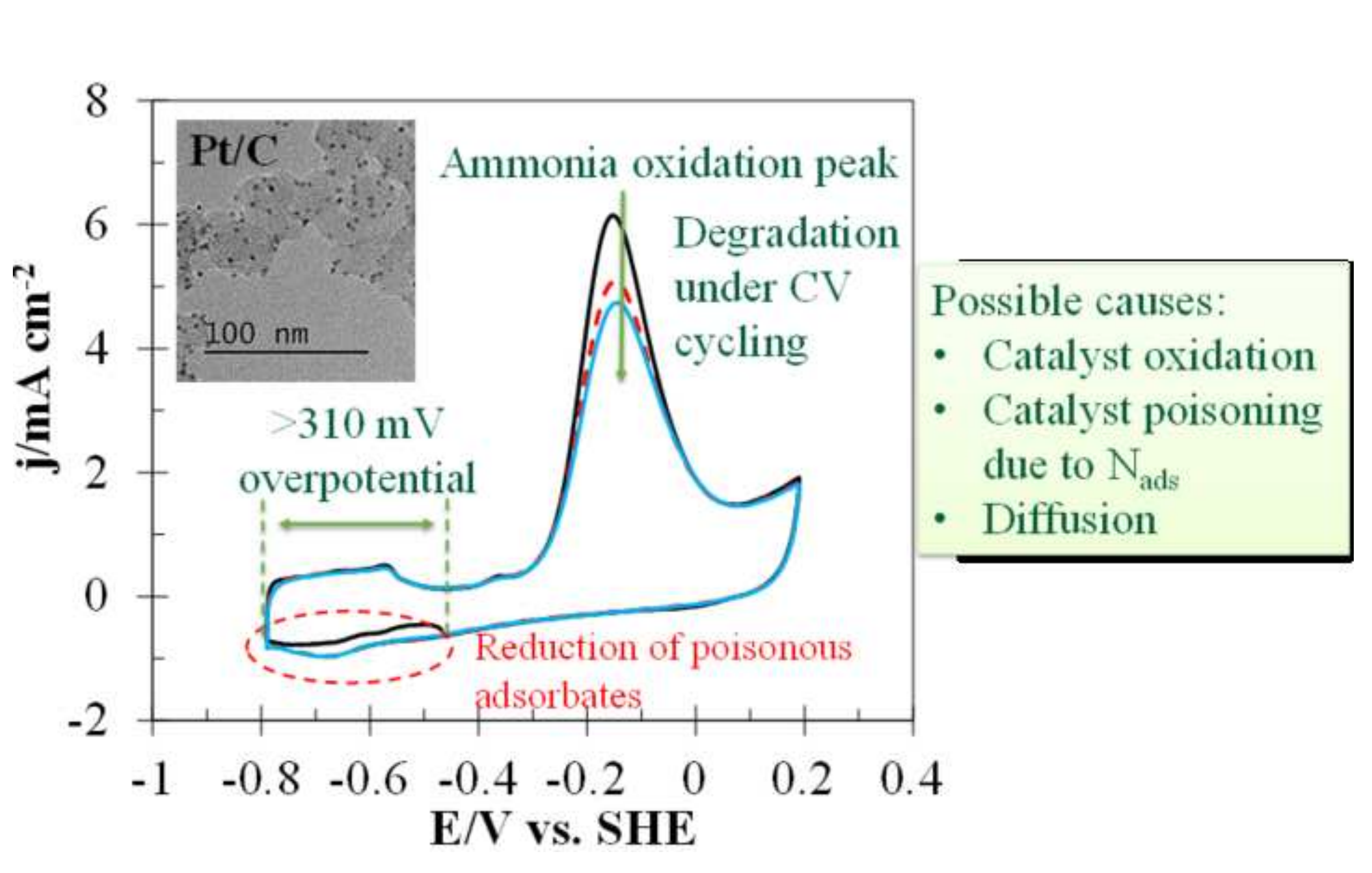


Figure 1
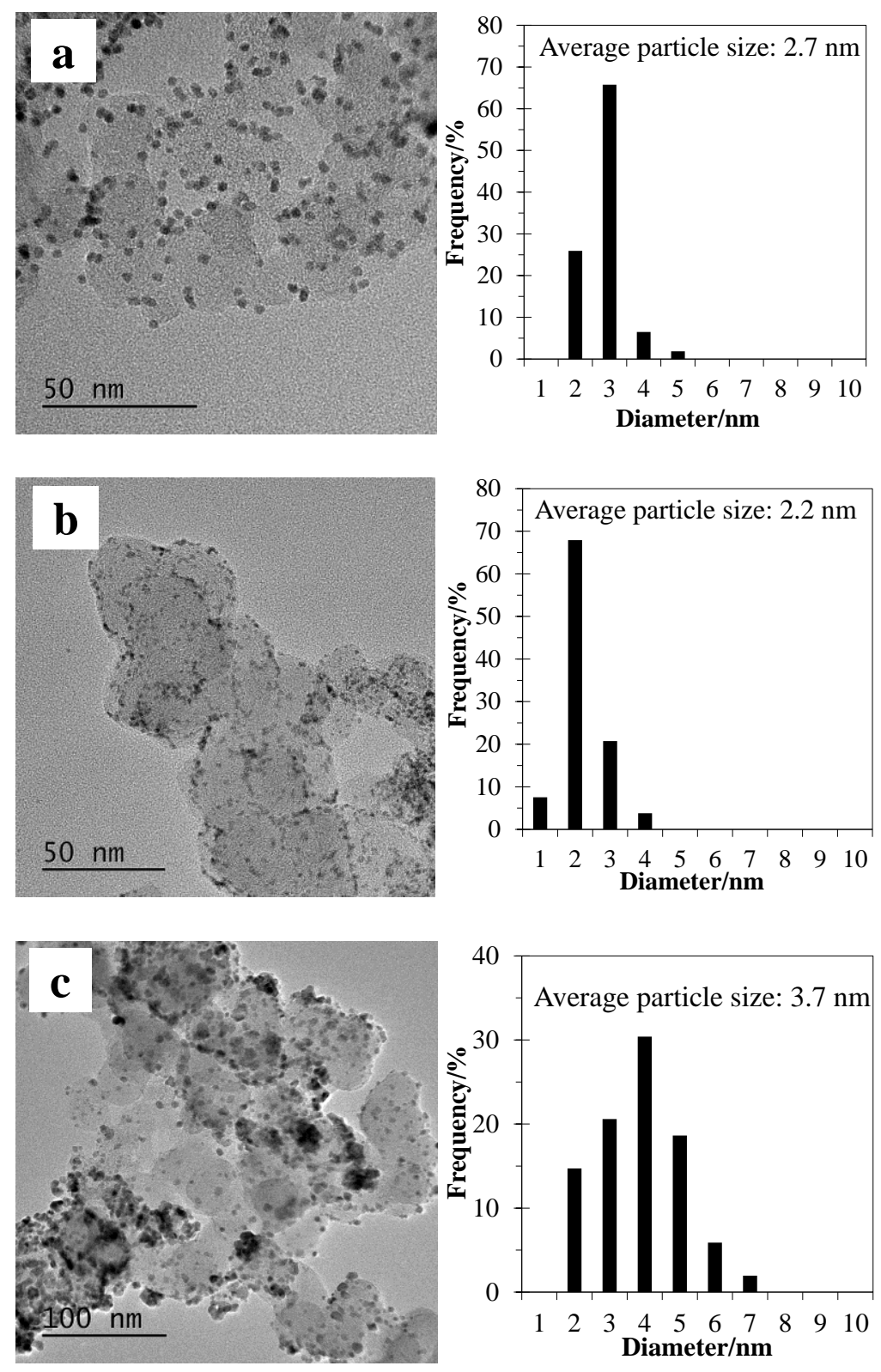

Figure 1. Li et al. 


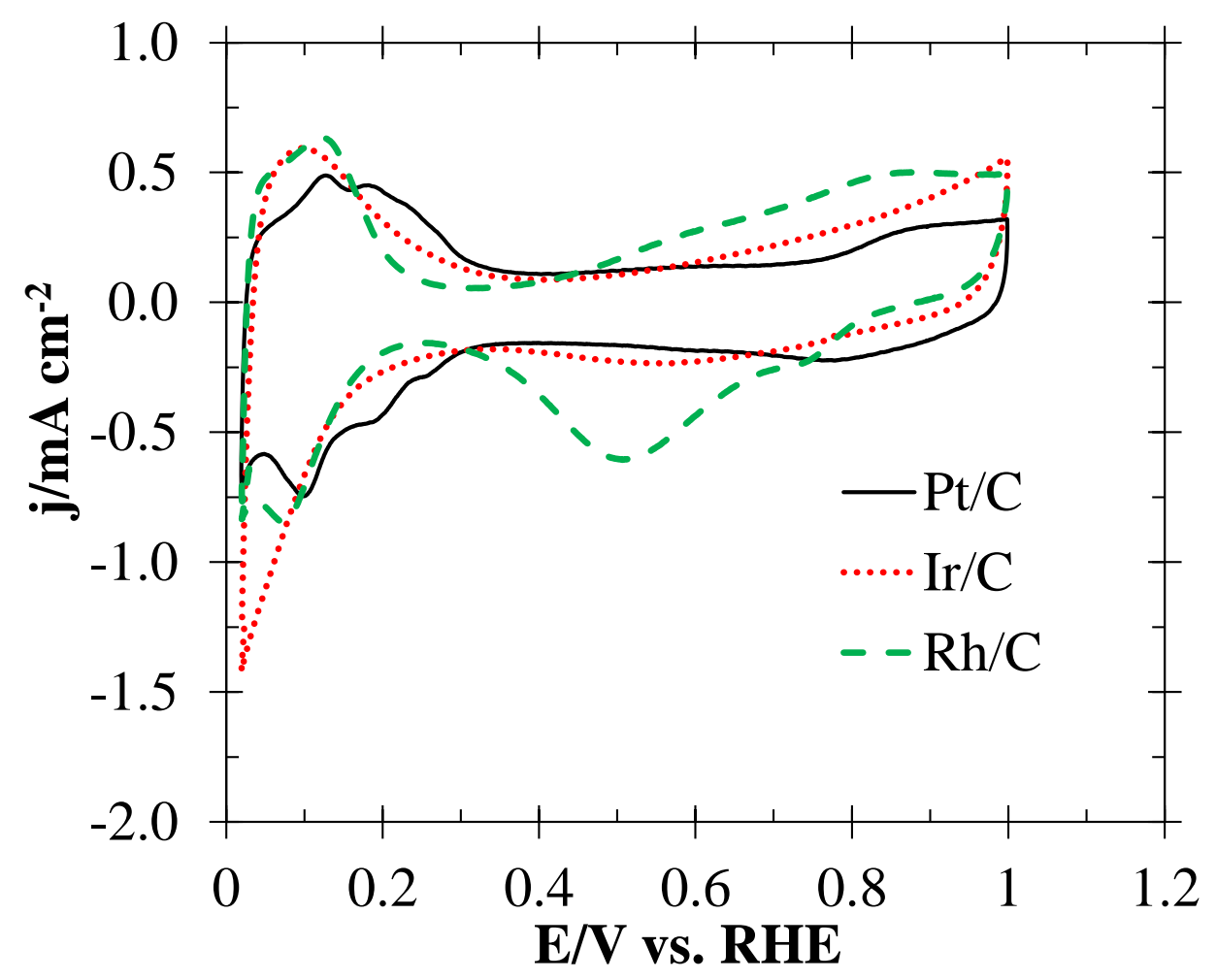

Figure 2. Li et al.

Figure 2 

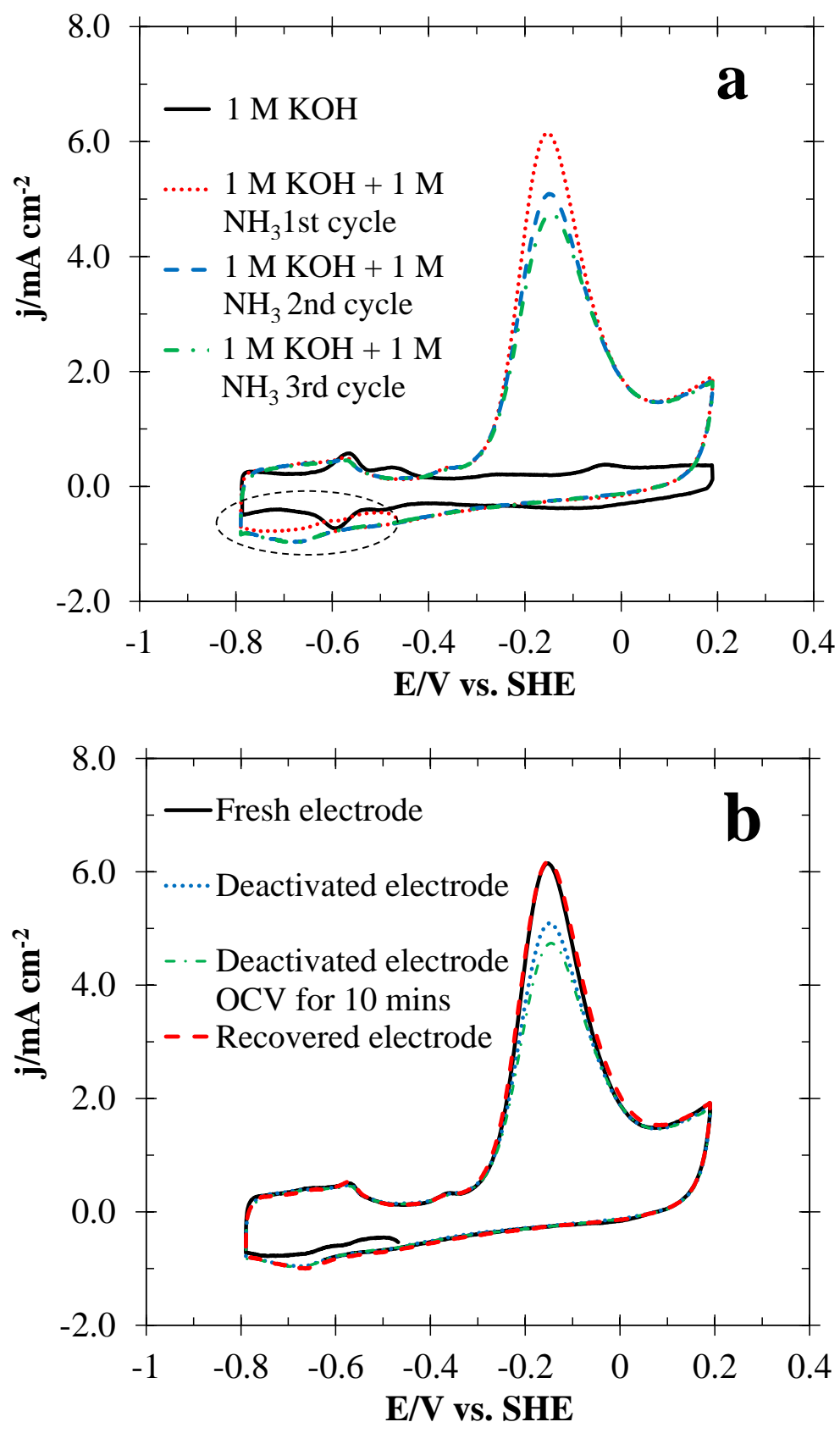

Figure 3. Li et al. 

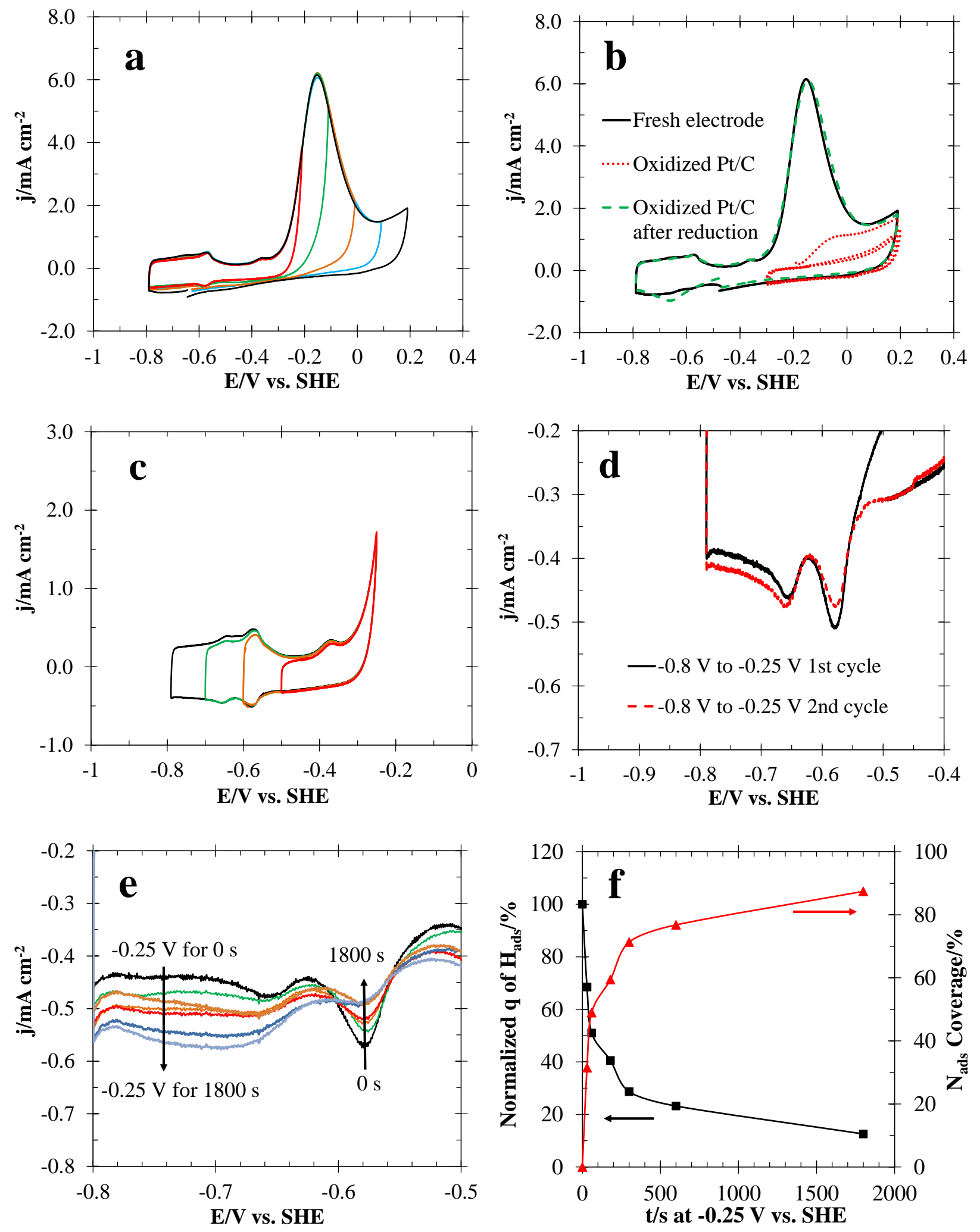

Figure 4. Li et al. 

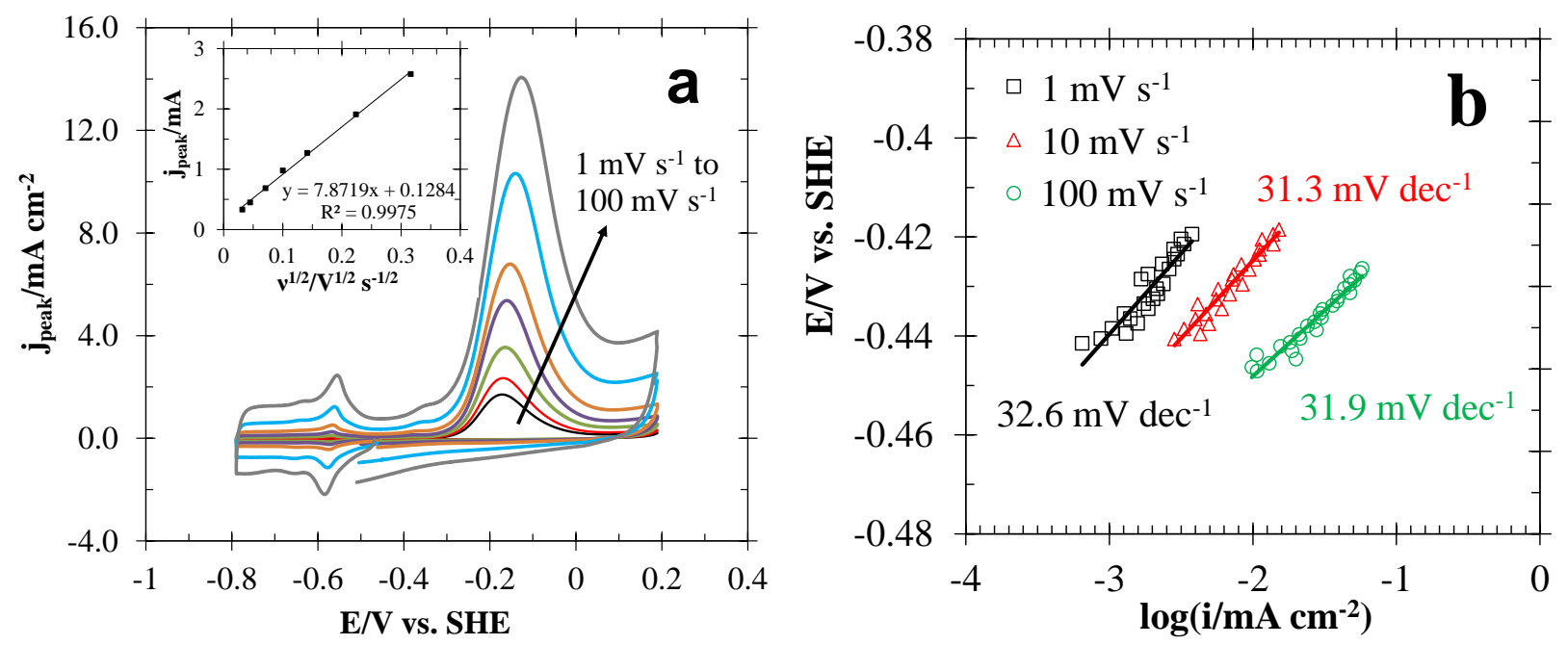

Fig. 5. 



Figure 6. Li et al. 

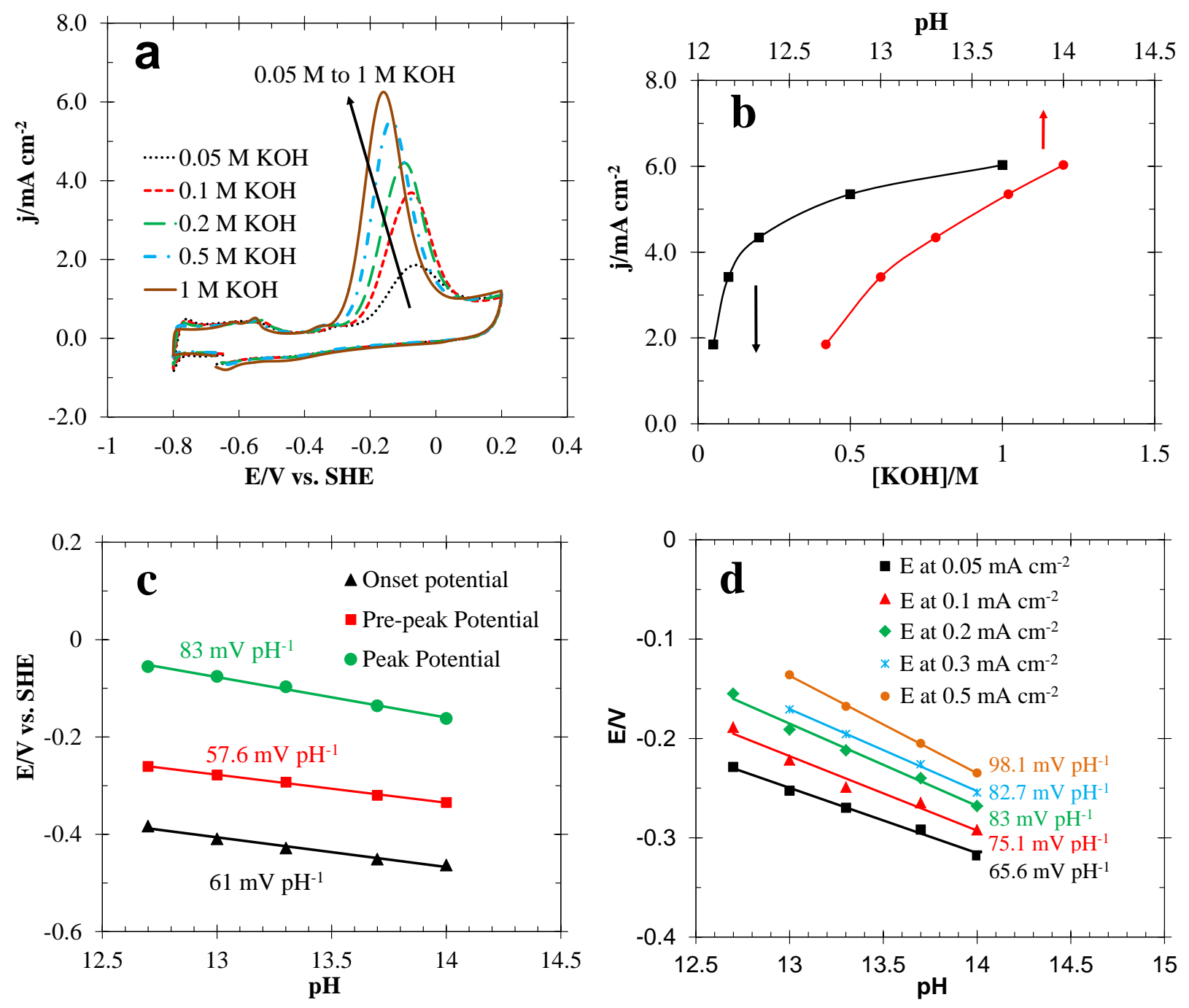

Fig. 7. 

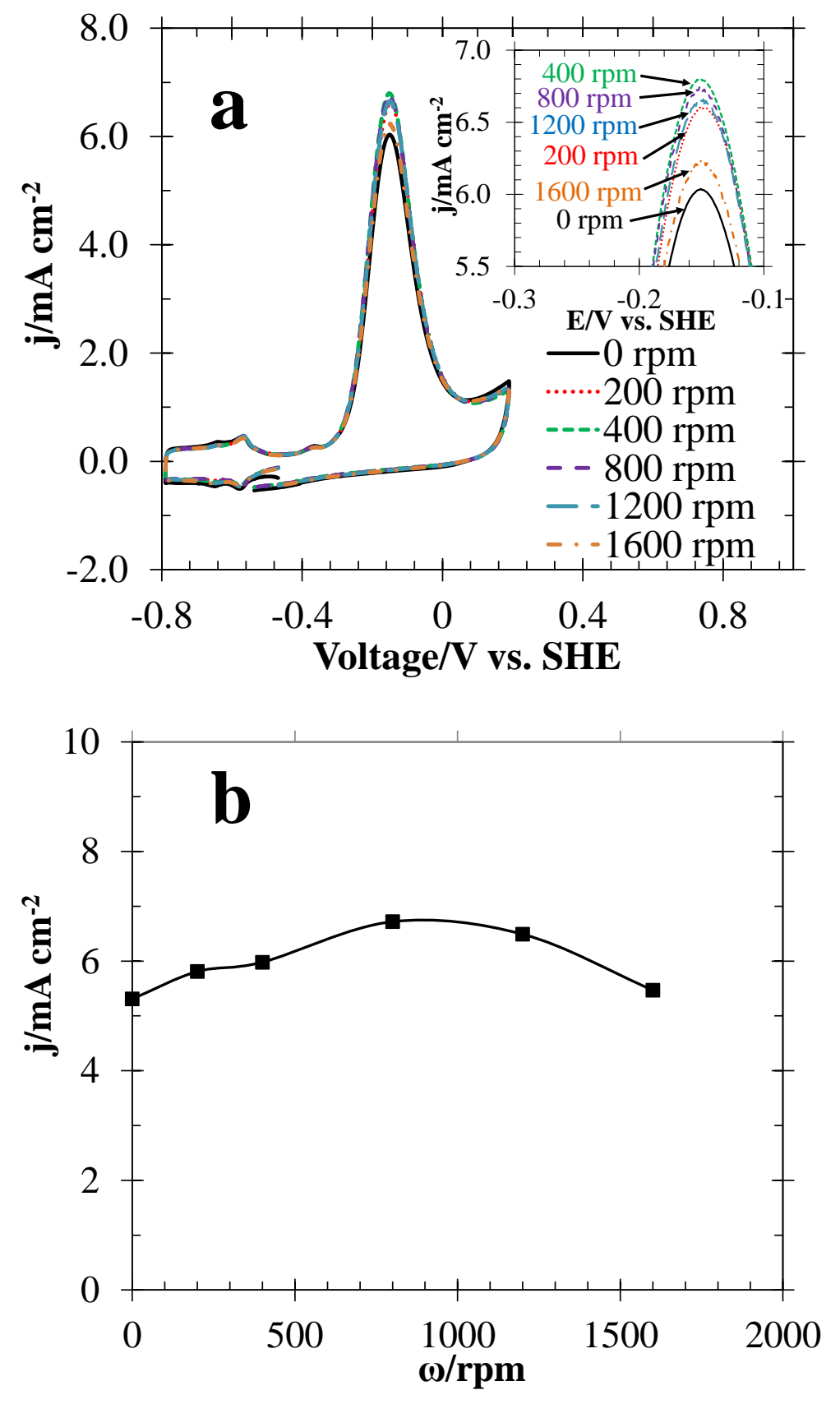

Figure 8. Li et al. 

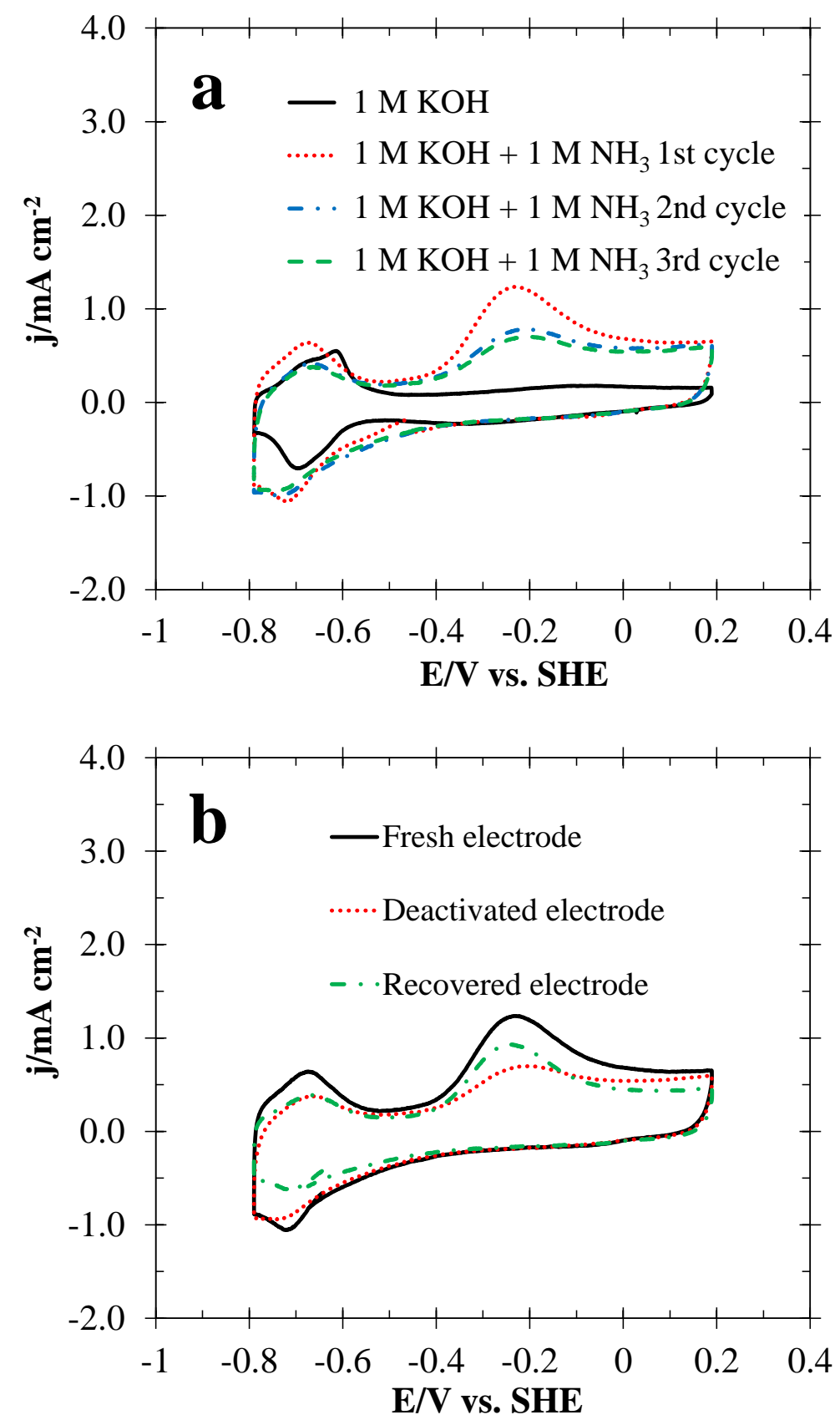

Figure 9. Li et al. 

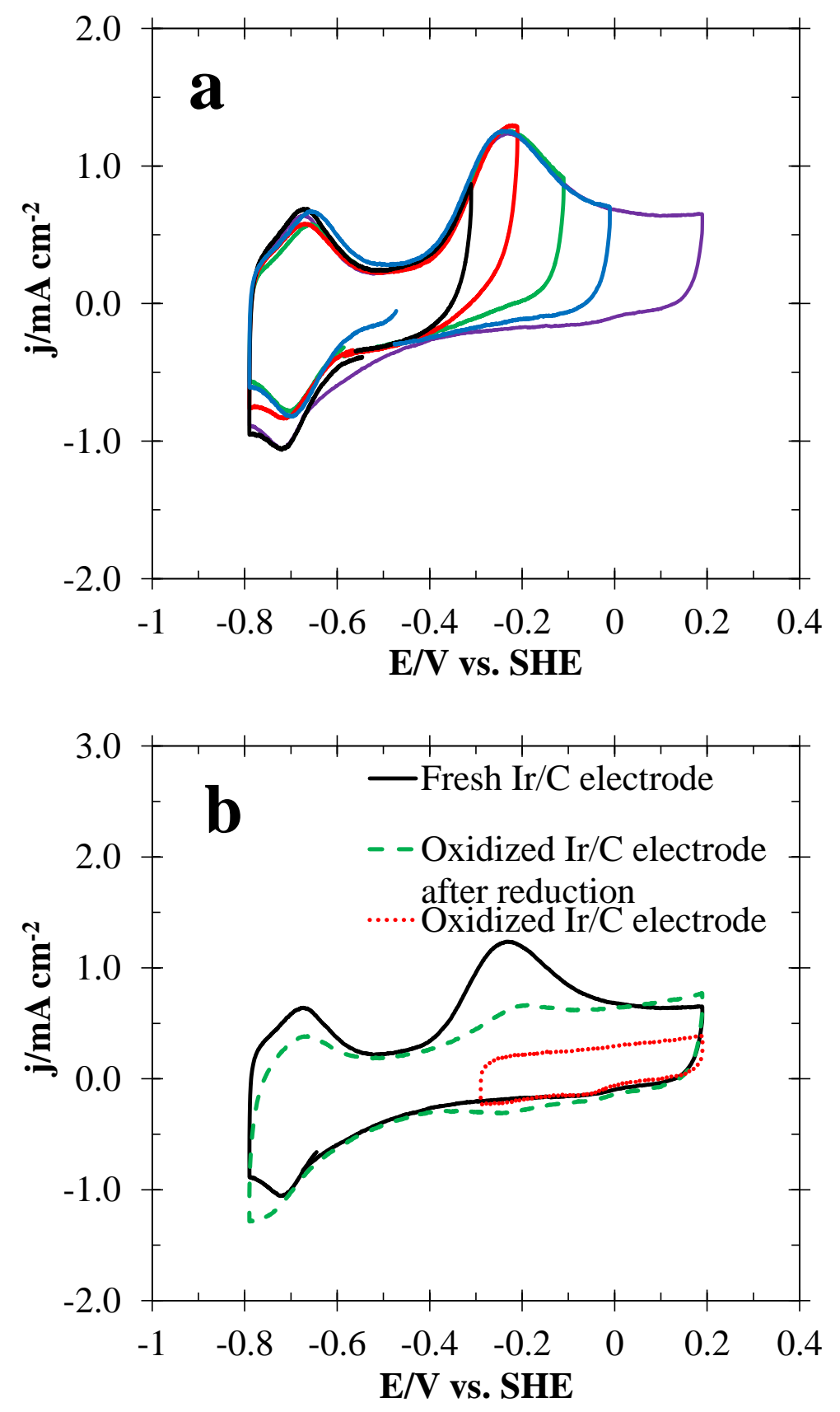

Figure 10. Li et al. 


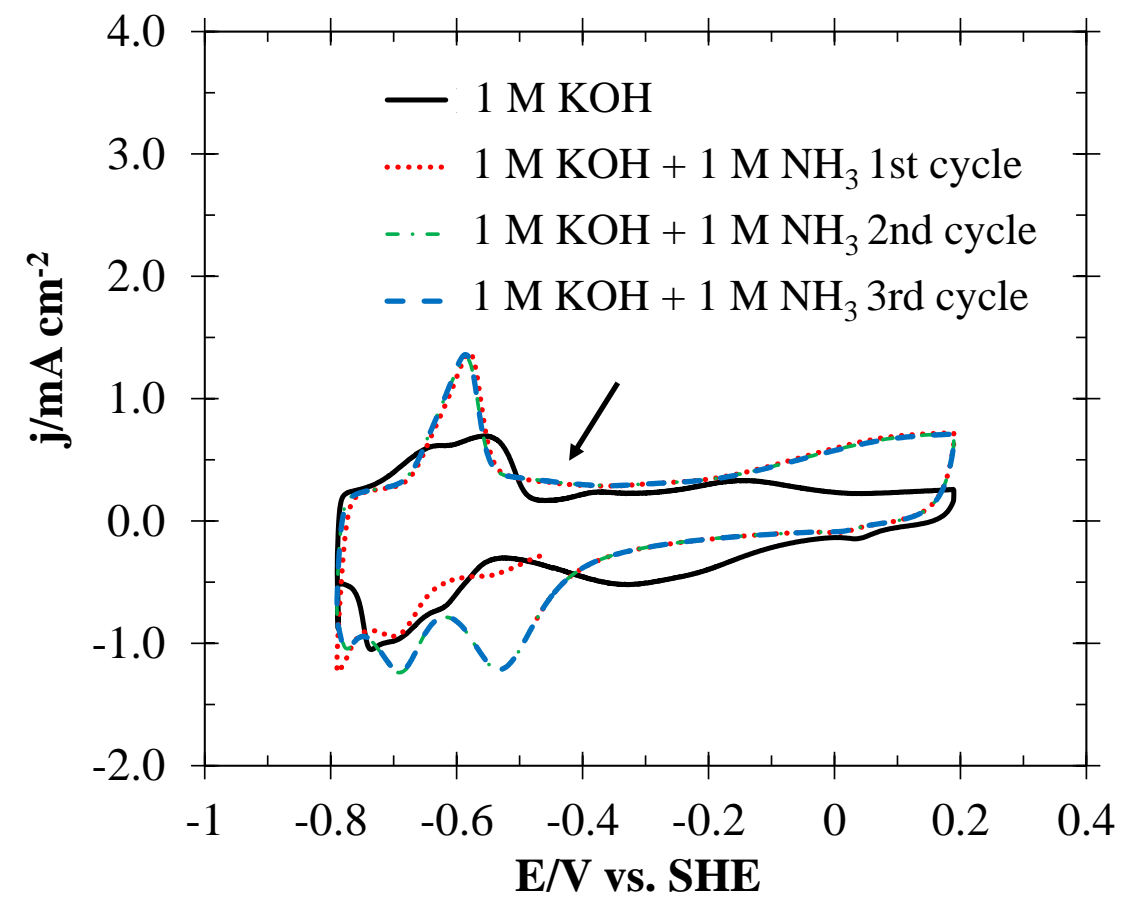

Figure 11. Li et al. 